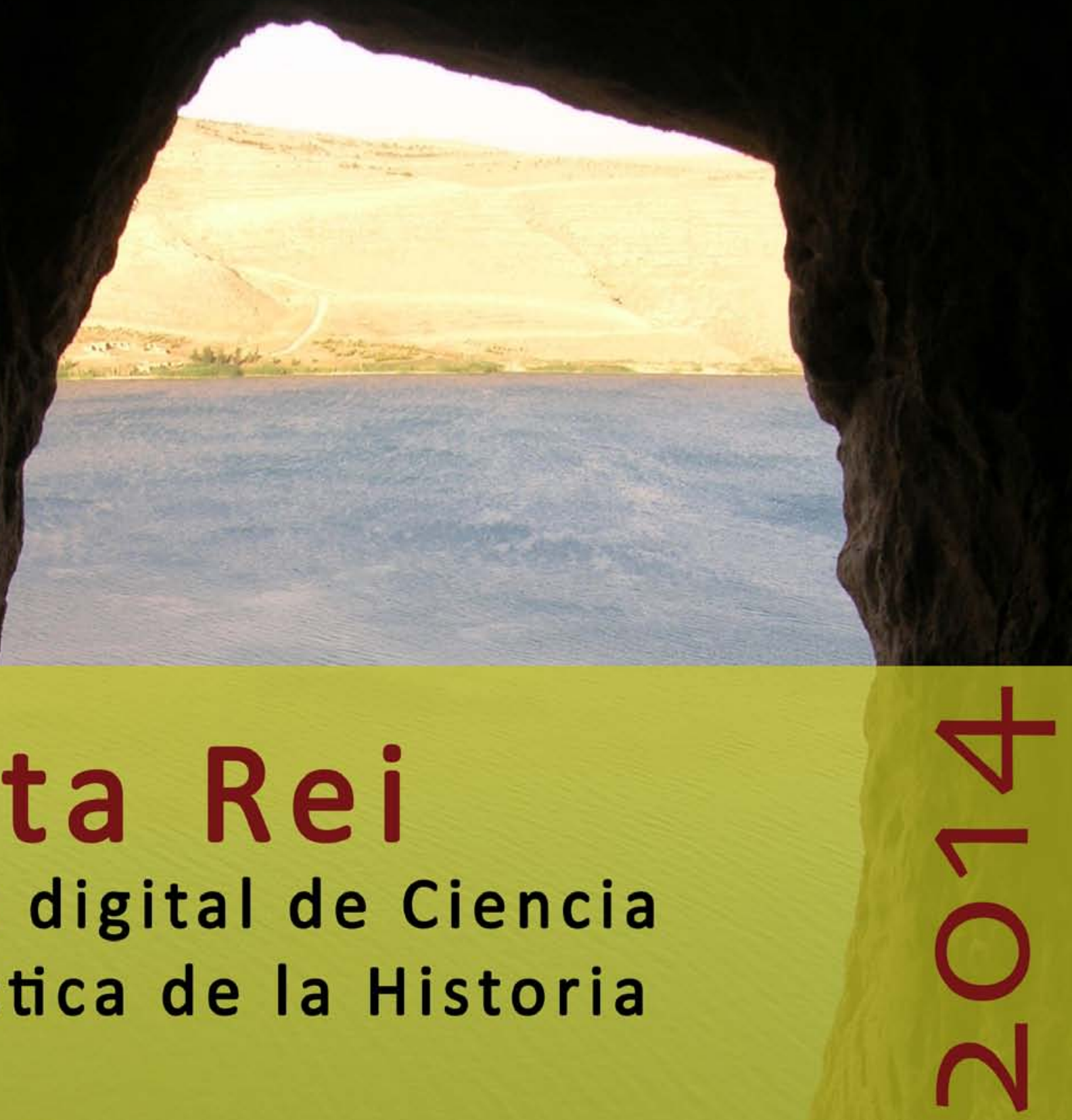





\section{Panta

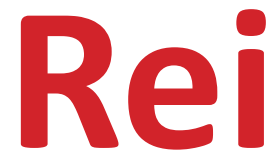 \\ Revista Digital de Ciencia \\ y Didáctica de la Historia}

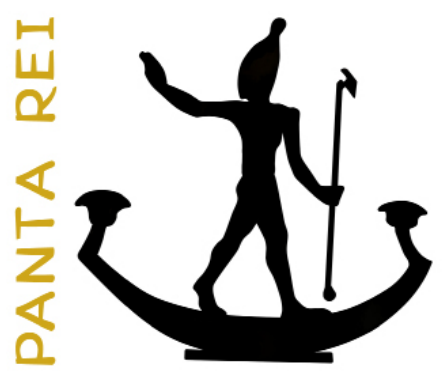

2014

Revista anual

Fecha de inicio: 1995

Revista Panta Rei. pantarei@um.es

\section{Edita:}

Centro de Estudios del Próximo Oriente y la

Antigüedad Tardía - CEPOAT

Edificio Universitario Saavedra Fajardo.

Universidad de Murcia

C/ Actor Isidoro Máiquez, 9

30007 - MURCIA - ESPAÑA

Teléfono: (+34) 868883890

cepoat@um.es

Web: www.um.es/cepoat/pantarei

Edición 2014

ISSNe: 2386-8864

ISSN: $1136-2464$

Depósito legal: MU-966-1995
cepoAt

UNIVERSIDAD DE MURCIA centro de estudios del próximo oriente y la antigüedad tardia

En Portada: Río Éufrates desde un eremitorio cristiano primitivo (Fotografía de Alejandro Egea).

Responsables de los textos:

Sus autores.

Responsable de la presente edición: Consejo Editorial Panta Rei. 


\section{CONSEJO DE REDACCIÓN}

\section{Coordinador editorial}

Egea Vivancos, Alejandro

[Didáctica de las Ciencias Sociales, UMU]

\section{Editores}

Botí Hernández, Juan Jesús

[CEPOAT, UMU]

Sáez Giménez, David Omar [CEPOAT, UMU]

\section{Secretaria}

Arias Ferrer, Laura

[Didáctica de las Ciencias Sociales, UMU]

\section{Responsable informático}

Martínez García, José Javier

[CEPOAT, UMU]

\section{Traducción y corrección lingüística}

Martínez Martínez, Cristina

[Sociedad Española de Lenguas Modernas]

\section{CONSEJO ASESOR}

Albero Muñoz, M. ${ }^{a}$ del Mar [H. ${ }^{a}$ del Arte, UMU]

Cobacho López, Ángel

[Derecho, UMU]

Egea Bruno, Pedro M. ${ }^{a}$

[Historia Contemporánea, UMU]

García Atienzar, Gabriel

[Prehistoria, UA]

González Monfort, Neus

[Didáctica de las Ciencias Sociales, UAB]

Haber Uriarte, María

[Prehistoria, UMU]

Irigoyen López, Antonio

[Historia Moderna, UMU]

Mahony, Simon

[Digital Humanities, UCL, Reino Unido]

Marsilla de Pascual, Francisco Reyes

[Técnicas historiográficas, UMU]

Miralles Maldonado, José Carlos

[Filología Clásica, UMU]

Molina Gómez, José Antonio

[Historia Antigua, UMU]

Noguera Celdrán, José Miguel

[Arqueología, UMU]

Pérez Molina, Miguel Emilio

[Filología Clásica, UMU]

Prados Martínez, Fernando

[Arqueología, UA]

Sánchez Ibáñez, Raquel

[Didáctica de las Ciencias Sociales, UMU]

Sancho Gómez, Miguel Pablo

[Educación, UCAM]

Vilar García, María José

[Historia Contemporánea, UMU] 
Presentación

Todo fluye. Renovarse y crecer

Alejandro Egea Vivancos, Laura Arias Ferrer, Juan Jesús Botí Hernández y David Omar Sáez Giménez

Artículos

La sociedad hiperbórea: ¿utopía o mito? Reflexiones acerca de la naturaleza y significado del relato hiperbóreo.

José Ángel Castillo Lozano.

Aproximación a la figura de una matrona romana culta y poderosa. El caso de Julia Domna.

Consuelo Isabel Caravaca Guerrero.

¡Arrasar la Vendée! Guerra Civil y Columnas Infernales en pleno corazón de la Revolución Francesa.

Benjamín Cutillas Victoria.....

Arte y expresión en el pensamiento de E. H. Gombrich.

Patricia Castiñeyra Fernández.

Odiseo a través de la parodia. Desmitificación e ironía de una Ítaca nostálgica en Prometeo de Pérez de Ayala y ¿Por qué corres, Ulises? de Gala.

Carmen María López López.

Análisis de la actividad didáctica del Museo de Arte Ibérico El Cigarralejo (Mula, Murcia).

Julio García Toral......

La Transición española en $4 .^{\circ}$ ESO. Un estudio de caso de los significados.

Borja Santiago Arnoso.

Entrevista

Entrevista al profesor D. Michael Walker.

Consuelo Isabel Caravaca Guerrero.

Reseñas

II Congreso de la Asociación Internacional de Investigación para la Educación de la Historia y las Ciencias Sociales.

Elvira Barriga y Rodrigo Salazar.

I Congreso de Jóvenes Investigadores del Mundo Antiguo de la Universidad de Murcia.

Pedro David Conesa Navarro

II Congreso Internacional de Educación Patrimonial.

Tània Martínez Gil.....

Ruiz-Gálvez Pliego, M. (2013). Con el fenicio en los talones. Los inicios de la Edad del Hierro en la cuenca del Mediterráneo. Barcelona: Editorial Bellaterra. 377 págs.

Celso Sánchez Mondéjar..

Normas de publicación/Publishing rules 



\title{
Análisis de la actividad didáctica del Museo de Arte Ibérico El Cigarralejo (Mula, Murcia)
}

\author{
Analysis of the educational activity of The Museum of Iberian Art El Cigarralejo
}

(Mula, Murcia)

\author{
Julio García Toral \\ Universidad de Murcia
}

Recibido: 05/03/2014

Aceptado: 21/10/2014

Para citar este artículo: García Toral, J. (2014). Análisis de la actividad del Museo de Arte Ibérico El Cigarralejo (Mula, Murcia). Panta Rei. Revista Digital de Ciencia y Didáctica de la Historia, 97-119.

ISSNe: 2386-8864

DOI: http://dx.doi.org/10.6018/pantarei/2014/7

\section{Resumen}

En el presente trabajo se ha llevado a cabo un análisis de las actividades y materiales didácticos producidos en el Museo de Arte Ibérico El Cigarralejo (Mula, Murcia). Identificados los materiales destinados a los niveles curriculares de la Educación Secundaria el objetivo ha sido establecer una radiografía de estos materiales y determinar su pertinencia educadora para el nivel educativo en cuestión y su grado de cumplimiento y seguimiento del curriculum. Todo ello se ha planteado con el fin de sistematizar la labor didáctica de El Cigarralejo y asentar un trabajo que permita en el futuro aportar nuevos planteamientos a la constante y prolífica acción didáctica de EI Cigarralejo.

\section{Palabras clave} básicas.

Didáctica, museo, patrimonio, educación no formal, Educación Secundaria, competencias

\begin{abstract}
On the present essay, it has been made an analysis of educational activities and materials made at El Cigarralejo museum during the last years, from which some conclusions have been proposed. The said analysis of materials has been made in order to obtain a study about what has been carried through at the museum in order to tell apart the educational materials from the ones designed for dissemination, and to tell the former apart from the ones designed for the first Compulsory Secondary Education year. From that classification of materials, it has been developed an in-depth analysis in order to get virtues, skills, and potential improvement.
\end{abstract}

\section{Keywords}

Didactic, museum, heritage, informal education, Secondary Education, key competences. 


\section{Introducción}

La didáctica del patrimonio sigue siendo una de las tareas pendientes de nuestra sociedad, no obstante en los últimos años se ha avanzado mucho en esa dirección, prueba de ello son museos como el que nos ocupa. El Cigarralejo es un ejemplo de lo mucho que se ha conseguido y del gran esfuerzo que ha habido que realizar para mantenerse al día ante una exigencia social tan creciente como demandada.

Sin embargo, la didáctica del patrimonio sigue siendo en muchos casos una asignatura pendiente. La todavía frecuente confusión de difusión con didáctica lleva al error de pensar que por publicitar y difundir los contenidos ya se está facilitando el acceso al patrimonio. Más error hay en ello si se llega a pretender que los contenidos adaptados para la difusión sirven como materiales didácticos.

Pero aun cuando se asimile que la didáctica del patrimonio es muy distinta a la difusión de este, es necesario dar un paso más allá en la concepción del museo como espacio de ocio. Un museo puede tener excelentes materiales didácticos pero no tenerlos en relación con su contenido. Será necesario que los museos tengan materiales didácticos propios, adaptados a sus necesidades y que transformen el museo en un lugar de ocio atractivo, donde la sociedad vea satisfechas sus demandas de educación y los alumnos abandonen por fin la idea del museo como un lugar estático, aburrido y en definitiva poco atrayente para el aprendizaje.

Será el propósito de este trabajo proponer, después de un exhaustivo análisis de los materiales del museo, ofrecer un panorama del estado actual de las actividades didácticas de El Cigarralejo como un museo donde la enseñanza y la labor didáctica han sido siempre los ejes de la actividad cotidiana del mismo. ${ }^{1}$

\section{La didáctica de los museos}

La llegada de la sociedad del bienestar, consumidora de ocio y con niveles culturales cada vez más elevados y sensibilizados con el pasado o con el arte, ha impuesto, en un plazo relativamente pequeño, una transformación sustancial de los museos como depósitos y expositores de sus colecciones a constituirlos en referentes educativos de primer orden. Además de la dimensión científica, ahora tendremos una participación de los visitantes cada vez más activa. La llegada de las nuevas tecnologías, especialmente las audiovisuales, ha ganado una importancia extraordinaria sobre todo si tenemos en cuenta su reciente incorporación a la vida diaria de nuestra sociedad. La dinámica de los museos estará en constante renovación, viva, deberá ser capaz de reaccionar a todos los cambios sociales de su entorno y ser adaptable a las exigencias de ocio y cultura cada vez mayores de la sociedad. Por primera vez los museos serán elementos de la industria del turismo, con un valor económico potencial enorme (Santacana y Serrat 2005).

Pero será su valor didáctico uno de los cambios más significativos acaecidos en época reciente. Según Fontal (2010), la didáctica del patrimonio se está configurando como una disciplina emergente, con una doble vía de desarrollo, por un lado como parte de las diferentes didácticas específicas siendo capaz de albergar miradas multi e interdisciplinares del conocimiento universitario y por otro, como una disciplina autónoma, propia, que comienza a crear su propia literatura, su especificidad, institutos de investigación propios, másteres y postgrados específicos.

La proyección educativa que los museos tratan hoy dia de dejar patente en sus exposiciones es el nuevo motor y el nuevo parámetro que criticamos y comentamos a la llegada a un museo. Departamentos, gabinetes, y personal cualificado se incorporan ahora a cada museo con el objetivo de educar empleando el valioso contenido de sus salas (Tugores, 2006).

1 Me gustaría agradecer a la directora del Museo de El Cigarralejo, doña Virginia Page del Pozo, su colaboración y su entrega, poniendo el museo a mi disposición y facilitándome todos los materiales didácticos; y al profesor Alejandro Egea, por su especial paciencia y dedicación. 
Y es que como dice Ballart (2007) el análisis de la historia de los siglos XIX y XX justifica en última instancia a los museos como institución educativa de manera que la idea de museo siempre quede ligada a la educación pues como afirma este mismo autor, el legado cultural o patrimonio cultural heredado por transmisión humana se constituye en una manera de mantener la relación entre una generación y la siguiente siendo este un efecto a escala universal. (Ballart, 1997).

Sin embargo, ¿por qué ahora se ha universalizado la idea de la educación y la didáctica en los museos?

Desde siempre los museos han estado en relación con la práctica educativa y se han visto influenciados fuertemente por ésta, hasta tal punto que los museos siempre han sido el reflejo de la tendencia educativa del momento. La tradición escolar ha mantenido hasta época relativamente reciente que el aprendizaje situaba al alumno como figura pasiva, mero receptor de los conocimientos que el profesor le iba trasmitiendo ordenadamente (Santacana y Serrat, 2001). El concepto tradicional de museo no dista mucho de esa definición. Grandes sales llenas de materiales y obras, ordenadas cronológica y o temáticamente y que el visitante ingería en sucesión y sin interacción ninguna con el museo. Más aún, la figura preeminente de los eruditos e investigadores especializados en la configuración y elaboración de la musealizaciones llenando estos las museografías con grandes cantidades de datos y elementos descriptivos produciendo exposiciones carentes de emoción, pobres y sin cumplir los objetivos de la museografía actual. El papel del asesor se confunde con el del guionista quedando así servido el fracaso (Santacana y Serrat, 2005).

Hoy en día esta metodología tradicional está siendo sustituida por la idea de raíz piagetiana de que el alumno juega un papel activo, que incluye una reordenación de los esquemas mentales propios con la construcción de nuevos significados y la extracción de conclusiones propias a partir de los datos ofrecidos (Ballart, 2007).

En este proceso de cambio han ido surgiendo nuevas ideas educadoras. El constructivismo desarrollado a partir del trabajo de Piaget (1983) y Vygotsky (Tryphon y Vonèche, 2000), entre otros, ha penetrado con fuerza en la escuela y en la mayoría de los museos con intención educadora. El constructivismo se asienta sobre dos supuestos: uno, que para que haya aprendizaje el alumno tiene que participar activamente y entrar en contacto con el objeto de aprendizaje y llevar acabo experimentación; dos, las conclusiones extraídas no tienen que estar refrendadas por una verdad exterior y superior sino que son válidas en sí mismas si tienen sentido en la realidad propia del alumno (Ballart, 2007). La influencia sobre los museos de todas estas transformaciones será decisiva y condicionará en buena medida el desarrollo de nuestros museos.

Por otra parte, las transformaciones sufridas por nuestra sociedad en las últimas décadas no son baladíes. La sociedades posindustriales han evolucionado (o están haciéndolo) hacia sociedades dominadas por la información. Hace unas décadas lo importante del sistema económico eran los productos, ahora lo son los servicios. En una sociedad donde el consumo de servicios se ha disparado, viene paralelamente a coincidir que ahora la cultura se ha hecho universal, todo el mundo quiere adquirirla, y lo que es más importante, ya no se entiende como algo a asimilar en los primeros años de vida, en los años de formación personal, ahora la cultura es algo que se busca constantemente, durante toda la vida, no tiene límite ninguno. La necesidad de aprendizajes nuevos no remite nunca, ni en el tiempo, ni en los diferentes ambientes sociales (laboral, familiar, social, etc.). El papel que ejerce en ello los medios de comunicación de masas es tremendo y en buena medida responsable de que las transformaciones hayan sido tan rápidas (García y Martín 2009).

Al siglo XXI los museos han llegado con una fuerza y un crecimiento enormes. En particular en nuestro país lo que se han llamado los años de bonanza ocasionaron un enorme crecimiento de la cultura y con ella de los edificios e instalaciones dedicados a esta. Sin embargo, como nos señala Santacana (2012) el crecimiento espectacular de los museos en nuestor país, principalmente en número y diversificación, ha sido sólo cuantitativo, aumentando su número pero no su calidad. Se crearon espacios y se construyeron edificios pero no se generaron equipos de investigación, de dinamización y por lo tanto se cercenó desde el principio toda suerte de innovación y mejora.

En efecto, cuando se inició la segunda década del siglo XXI y la crisis económica alcanzó de 
lleno a nuestro país, la sociedad se encontró con decenas de centros y museos vacios de contenido, muy caros de mantener y sin equipos detrás que pudieran con su trabajo e innovación mantener activos y productivos estos centros. Se había producido, lo que Santacana (2012) ha señalado acertadamente como la "burbuja de la cultura museística".

Así mismo, como diceHernández (1998), la posmodernidad ha llevado a la cultura a convertirse en industria y por lo tanto se espera de ella que produzca riqueza. Los museos pasan ahora a convertirse en centros culturales para las masas, entrando a competir directamente con toda la oferta de ocio social y transformando su oferta en una capaz de captar al mayor número posible de grupos sociales. En la actualidad asistimos a lo que autores como Pozo (2012) han definido como una crisis de la cultura humanística. Una crisis de la cultura de la civilización y por lo tanto de la identidad de las personas de nuestra sociedad. En este marco de crisis económica y eclosión de crisis culturales anteriores se han visto envueltos nuestros museos, con resultados nada deseables en tanto en cuanto que refugios de la cultura-civilización que define Pozo (2012).

En el mismo sentido, el avance constante de la democracia cultural ha producido la masificación y subsiguiente banalización de la cultura. El crecimiento de la población, los movimientos migratorios han hecho que la industria de la cultura, que asienta sus bases en el ocio y el entretenimiento, amplíe notablemente su oferta cultural ante un público expansivo que demanda cultura para sus momentos de ocio, y que ve en los libros, los museos y la música una forma más de realización personal. La globalización cultural y a su vez la inherente individualidad personal hacia el ocio y la cultura que impone cada persona han creado un marco de competencia interna que está dando pie a sucesivas iniciativas y diversas ofertas culturales (Hernández, 1998).

Por otra parte, Hernández (2002) señala el camino que en muchos casos se ha seguido y luego se ha tenido que desandar es el que lleva a cabo una musealización muy compleja y elaborada, con gran inversión en recursos y de un carácter fuertemente innovador pero desconectada por completo del objeto a musealizar. La museografía adecuada es la que está ligada a la didáctica y la que se ha de imponer. Si bien la sociedad demanda cultura, esta ha de llegar en un formato adaptado, atractivo y sobre todo instructivo. Si no hay comunicación, si las musealizaciones se desarrollan al margen de la lógica de la didáctica, estarán condenadas al fracaso.

Tejera (2012) señala que la educación histórico-artística sería la formación de unos ciudadanos comprometidos con la protección y conservación del patrimonio histórico-artístico, y lo desglosa en tres objetivos: capacitar a los individuos para tomar conciencia de las cualidades estéticas que tiene el patrimonio histórico-artístico y el entorno en el que vivimos; capacitar a los estudiantes para comprender que en el arte existe una conexión entre el contenido, la forma, la cultura y el tiempo en que fue creado cada elemento patrimonial; y desarrollar habilidades y destrezas para reconocer y aceptar las múltiples perspectivas que los objetos patrimoniales poseen.

Y es que la didáctica es la que debe llevar la batuta en la configuración de los museos para servir de plataforma para lo más importante, que el museo se convierta en una prolongación del aula, en un instrumento más al servicio del profesorado. Como dice Santacana y Piñol (2010), el museo resultará un espacio útil para el desarrollo del trabajo procedimental, no para el desarrollo en bruto del guión de las clases. Hay que ir al museo a resolver enigmas, problemas, a buscar modelos o hipótesis sobre los hechos o las cosas, a aprender a clasificar, ejercitar el juicio crítico, aprender a comparar, etc.

En definitiva y como enuncia Asensio (2003) en los últimos años el patrimonio ha ido basculando de ser un elemento pasivo que carga las arcas del Estado de forma cada vez más asfixiante a considerarse lo contrario, un activo en crecimiento que genera recursos y que se está convirtiendo en un elemento central de eventos sociales, políticos y económicos. El tiempo libre se llena de aprendizajes elegidos voluntariamente.

Ballart (2007) señala cómo los museos hoy en día se orientan cada vez más al público. Hay razones económicas de fondo pero éstas no llegan a explicar del todo la permanencia y fortaleza de una antigua relación ente museos y sociedad basada en la aceptación social del papel educativo concedido a los museos. Hoy existe un vínculo renovado que reconoce en los museos una dimensión 
educativa con miras más amplias y ambiciosas. Las instalaciones, el personal y los contenidos de los museos ofrecen marcos cada vez mejor adaptados a las demandas de aprendizaje y educación que pide la sociedad y que servirán para estimular esa necesidad de educación a lo largo de toda la vida.

Por otra parte el conocimiento y el respeto del patrimonio (Fernández, 2003) requiere educación en valores, por lo que su conocimiento no es un fin en sí mismo, sino un medio para trabajar las relaciones sociales y es aquí donde la didáctica del patrimonio ganará sentido y objetivo y donde se verá su enorme potencial educativo..

Hoy en día la clave para la gestión educativa y la didáctica en los museos se centrará en la persona que lo visita, en sus características propias. El contenido del museo deberá adaptarse al visitante, al alumno (sea de la edad que sea) que acude al museo en busca de educación. En definitiva el contenido del museo ha dejado de marcar el ritmo o el modo de aprendizaje, es el individuo quien condicionará el aprendizaje y es esta circunstancia la que está haciendo a los museos transformarse cada vez más, en su búsqueda constante de conexión con la sociedad. Como dice Asensio (2003), un museo es cada vez menos lo que tiene y cada vez más lo que hace.

\section{El museo como espacio educativo diferente}

El museo es un espacio educativo diferente de los centros educativos ordinarios. En los museos la oferta educativa debe ser distinta, para empezar porque la temática es específica, y no suele ser tan abierta o total como el contenido del currículo oficial. Además, muchos museos, como es el caso del museo que nos ocupa, son monográficos, dedicados exclusivamente a una temática específica, que tendrá unas características formales que lo definirán y que acotarán sus posibilidades pedagógicas. Son además espacios normalmente muy estáticos, donde todo el contenido está expuesto con solemnidad, distante, buscando manifestar su grandeza y su importante significación. Este carácter museográfico está en claro retroceso en nuestros días, donde la llegada de las nuevas tecnologías ha acercado notablemente los museos al nivel de sus visitantes buscando ofrecer salas y contenidos más adaptados al público general (Estepa, 2001).

En este sentido, Suárez, Gutierrez, Calaf y San Fabían (2013) señalan que en la actualidad, el recurso de la educación no formal, es decir la educación no impartida dentro del marco de las instituciones educativas y sus instalaciones, está cogiendo cada vez más peso en los programas de los docentes con el fin de dinamizar la educación y mitigar algunos problemas de falta de diversidad de los programas educativos.

Sin embargo, la renovación de los espacios museográficos es una cuestión muy compleja. Por un lado está la complejidad científica de modificar el discurso museográfico y el riesgo de alejar los contenidos del límite que el rigor científico permite. Por otra parte tendremos el coste económico que siempre suponen las renovaciones museográficas, muy elevado, en particular si tenemos en cuenta el papel central que han alcanzado las nuevas tecnologías. Su uso es casi obligatorio, pero su coste y su mantenimiento las hacen inviables para los pequeños museos. Por último hay que comprender que en nuestros días, tanto la museografía como la didáctica, son dos conceptos que están en pleno desarrollo y crecimiento y a las que se exige complementarse en el seno de los museos mutuamente en una relación tan compleja como variable (Serrat, 2005).

Por todo ello, museos como El Cigarralejo son ejemplos de adaptación constante, ya que a través de su gabinete didáctico y una notable y constante inversión de trabajo, mantienen una renovación continuada y sostenida de sus materiales didácticos para todos los niveles, cuya adecuación pedagógica es un éxito para los niveles de Infantil o Primaria y se encuentra todavía en desarrollo, como veremos más adelante, para los niveles de la Educación Secundaria.

Esta limitación, en su vertiente económica, ha sido salvada por El Cigarralejo con trabajo y dedicación constantes y se ha constituido como el único medio eficaz para mantener actualizada la didáctica del museo sin recurrir a costosas modificaciones museográficas.

Sin embargo, para que las actividades didácticas fueran plenas, las actividades deben 
relacionar directamente a los sujetos del aprendizaje con los contenidos curriculares a través del análisis directo de la colección. Es de vital importancia que actividades, exposición y alumnos sean un todo, necesarios como conjunto para el éxito de la docencia en el museo. Para que una actividad sea verdaderamente un acierto en el marco de un museo esas tres partes, actividad, exposición y alumno deben ser necesarias de manera que no haya actividad sin relación con la exposición o exposición sin relación con el alumno. Domínguez (2003) señala que si bien un museo debe ser un depósito de objetos que hay que proteger, restaurar, investigar y exhibir, no menos importante es que se constituya en un lugar de comunicación, diálogo y distracción. El museo ahora es un lugar de reunión, de relaciones sociales, de descubrimiento. Importará el "quién visita el museo" más que el "qué está expuesto". En esta línea los museos serán ahora espacios de desarrollo de experiencias, lugares de reunión y de aprendizaje de habilidades (Domínguez, 2003).

Dicho esto volvemos a la idea ya expuesta anteriormente de que el museo es un espacio de ocio donde lo que se busca es aprender. El acceso a la cultura que los museos proporcionan está relacionado directamente con el entretenimiento. Esto es así por muchos motivos, siendo el principal de ellos la necesidad social existente de consumo de educación desarrollada anteriormente. Yendo más allá, los museos y las actividades pedagógicas allí ofertadas deben ser necesariamente actividades de tipo lúdico, para que despierten el interés del alumno por el contenido del museo y así conseguir un aprendizaje de calidad. Como dice Coca (2010) la implicación social mayor sobre los museos ha estimulado la aparición de ofertas educativas y actividades dedicadas en un primer momento a la inclusión social pero que luego se han expandido a una oferta educativa más genérica.

La labor didáctica de El Cigarralejo se ha construido en el entorno de la idea de que enseñar divirtiendo es el mejor camino para conseguir este protagonismo del alumno y donde el museo quede como un lugar al que volver, que suponga una novedad interesante y divertida en la vida diaria del alumno y se aleje definitivamente de los estereotipos de lugar estático y aburrido donde su papel es pasivo y donde figura como agente secundario.

\section{El Museo de Arte Ibérico de El Cigarralejo}

El Museo Monográfico de Arte Ibérico de El Cigarralejo alberga la colección donada en 1986 por el Ingeniero de Caminos Canales y Puertos don Emeterio Cuadrado Díaz. La colección está formada por los materiales obtenidos a lo largo de 40 años de excavaciones en la necrópolis ibérica de El Cigarralejo, período en el cual se exhumaron 547 tumbas de incineración con una cronología que oscila entre los inicios del s. IV a.C y las primeras décadas del s. I a.C. (Page, 2003).

El Estado aceptó la donación el 21 de abril de 1989 a la misma vez que se crea el Museo El Cigarralejo en Mula, de titularidad Estatal con el siguiente objetivo: "Para la conservación, investigación y exhibición de todo y cuyo objeto específico es el mejor conocimiento de la cultura ibérica a través del estudio, la contemplación y el uso educativo de los materiales arqueológicos procedentes de El Cigarralejo (Page, 2003).

El Cigarralejo es un yacimiento arqueológico de época ibérica compuesto por necrópolis, poblado y santuario. De estas tres partes se han realizado campañas de excavación arqueológica en la necrópolis, excavada en su mayor parte, y en el santuario.

El museo dispone de dos edificios anexos y vertebrados en su lado común para formar el conjunto que es el Museo de El Cigarralejo. El edificio principal tiene en su planta inferior el acceso o recibidor de entrada; una gran sala de usos múltiples, donde se llevan a cabo desde exposiciones temporales hasta ciclos de conferencias; la biblioteca, el taller de didáctica y las áreas administrativas y de dirección; y una planta superior donde se expone la colección permanente del museo. En el jardín situado en el patio del edificio podremos encontrar una reproducción del encachado de la sepultura $\mathrm{n}^{0} 138$.

El edificio auxiliar está formado por las dependencias destinadas a la investigación y a la restauración y conservación de los materiales del museo. Podremos encontrar almacén, laboratorio de restauración, zonas para la acogida temporal de investigadores, etc. 
El museo cuenta con una exposición permanente dividida en 10 salas. Como nos señala Page (2003), a lo largo del recorrido se puede ver de forma paralela una secuencia cronológica de más de 80 ajuares funerarios y una muestra didáctica acerca de las características sociales, económicas y culturales del mundo ibérico, mediante la visualización de tumbas completas o de conjuntos de objetos característicos extraídos de diversas tumbas.

La composición de las salas se puede resumir muy brevemente en las siguientes temáticas: Sala I: historiografía de la necrópolis y las excavaciones. Sala II: jerarquía social. Sala III: agricultura. Sala IV: ganadería. Sala V: cerámica ibérica. Sala VI: industria textil. Sala VII: comercio y transporte. Sala VIII: dedicada en paralelo a la mujer ibérica y a la escritura. Sala IX: el guerrero. Sala X: muestra el resumen de la necrópolis y del mundo ibérico en general.

Pese a la temática transversal de cada sala, los materiales expuestos están mayoritariamente agrupados por sepulturas y siempre ordenados cronológicamente de manera que en la práctica totalidad del museo el visitante siempre contempla simultáneamente aspectos concretos de la sociedad ibérica a través de la configuración particular de una o varias sepulturas expuestas completas y bien diferenciadas.

\section{Metodología}

Para la realización de este trabajo ha sido necesaria una planificación previa exhaustiva de los recursos que iban a ser empleados en su elaboración. Desde una búsqueda completa de fuentes bibliográficas, pasando por una lectura inicial sobre el tema en cuestión para organizar el índice y ajustar los objetivos, hasta la visita del Museo de El Cigarralejo para la consulta y estudio del material didáctico del museo, el análisis de las instalaciones, tanto las comunes como la sala/taller de didáctica, y la entrevista con la directora y los responsables del departamento de didáctica del mismo.

Siendo el objetivo el estudio, análisis y en su caso crítica de las actividades del museo orientadas a la Educación Secundaria para, seguidamente, elaborar unas conclusiones que arrojen luz sobre su labor y la acción didáctica que se lleva a cabo en el museo anualmente. Finalmente, dejar el camino expedito para que más adelante se puedan proponer actividades enmarcadas con más precisión y utilidad en los programas educativos.

En una primera visita se entrevistó al personal pertinente del museo y se visitó las instalaciones del mismo, poniendo especial atención en el gabinete didáctico y en la sala/taller del museo, con lo que se obtuvo una idea preliminar de los recursos disponibles, del uso que se daba de los mismos y de la metodología de trabajo del propio museo.

En la segunda visita el objetivo fue iniciar el análisis de los materiales allí generados para su clasificación entre los didácticos y los "no didácticos" (Fernández, 2003)². El Museo de El Cigarralejo es un centro que ha generado en los últimos años mucha documentación relativa a su colección museística, a la Prehistoria, a la arqueología, etc. Siendo así, era necesario clasificar el material para descartar como "no didáctico" aquellos materiales que por su objetivo, su configuración y el nivel cultural no iban dirigidos a actividades didácticas propiamente dichas. Es el caso de la revista del museo, de formato puramente científico, los sucesivos catálogos del mismo, los trípticos del museo para su colección permanente y las exposiciones, tanto el trimestral como los especiales de Navidad y el "día de los museos" que incluyen la programación específica de esos periodos, y en general todo el material editado por el museo con fines divulgativos y únicamente informativos.

2 En el sentido de lo expuesto y para aclarar el término "no didácticos", Fernández (2003) nos dice lo siguiente: "En el campo de las humanidades (geografía, arte, historia, antropología,...) parece mucho más fácil acomodar estos conocimientos a la divulgación. Pero esta no es la realidad. Se parte muchas veces de principios generales que no encajan en el marco concreto estudiado y fácilmente en lugar de divulgar se vulgariza. Es fácil opinar, dar juicios de valor, etc. sobre hechos históricos, sociales sin documentarse, sin seguir un método científico, sin una intervención didáctica." 
Separados estos materiales de los propiamente didácticos el siguiente paso fue la clasificación de estos. Se los clasificó por formatos: experiencias didácticas, pasatiempos y talleres. Diferían notablemente los unos de los otros.

En este punto de la clasificación quedó claro que solo las experiencias didácticas son actividades dedicadas íntegramente a niveles de la Educación Secundaria por lo que se decidió dedicar todo el análisis y el trabajo de investigación a este grupo. No obstante, sí se llevó a cabo un análisis preliminar de todos los materiales estudiados:

- Las experiencias didácticas son los materiales de más alto nivel orientados en principio a la Educación Secundaria y Bachillerato.

- Los pasatiempos son actividades que tocan todos los niveles de Primaria e Infantil. Su variabilidad es enorme y a diferencia de las experiencias didácticas no siguen un formato concreto lo que lleva a que son unos materiales muchos más versátiles y flexibles a la recepción de alumnos en el museo, no obstante, en general orientados a niveles de primaria.

- Los talleres se condicionan de partida para el público al que irán dirigidos. La clasificación tuvo que ser casi taller a taller, aunque como es normal la mayoría de los talleres se localizaba en Infantil y ciclos de Primaria.

Organizados todos los materiales el siguiente paso fue su discriminación por materiales dedicados a la Educación Secundaria y a otros niveles educativos. Como ya se ha dicho antes, las experiencias didácticas serán el grupo de materiales sobre el que se llevará acabo el análisis y la investigación.

Dentro de las Experiencias Didácticas, primero se analizó la relación de las diferentes partes de las actividades. Textos, ejercicios, imágenes, etc., con el nivel educativo al que iban dirigidas. Para ello, se identificó en primer lugar aquellas actividades que requerían lecturas de textos de media extensión con léxico específico y presumiblemente nuevo para todo alumno que se enfrentase a él y que por lo tanto van orientadas a niveles educativos más elevados de la Educación Secundaria. En segundo lugar se atendió al tipo de actividad en sí, y al nivel de dificultad que iba a plantear su desarrollo para el alumno medio determinando también desde esta perspectiva qué actividades van más orientadas a niveles altos de la Educación Secundaria de aquellas que por su desarrollo son propias de niveles inferiores.

En segundo lugar, una vez situadas las actividades en sus correspondientes niveles curriculares por dificultad, procedimos a clasificarlas por adscripción del contenido al nivel curricular establecido por la legislación vigente. De esta forma hemos podido determinar el nivel de correlación de las actividades con el curriculum y con las edades o niveles educativos en los que se sitúan. Hay que señalar, que por su temática monográfica, el Museo de El Cigarralejo, desarrolla la mayoría de sus Experiencias Didácticas sobre la cultura ibérica que se sitúa en el nivel curricular de Primero de la Educación Secundaria, tal y como señala la legislación vigente.

A continuación mostramos una de las tablas que se elaboraron para la realización del análisis de las Experiencias Didácticas del Museo de El Cigarralejo clasificando sus elementos por los niveles educativos a los que van orientadas en base a sus características formales y su desarrollo. 


\begin{tabular}{|c|c|c|c|c|c|c|c|}
\hline & & Infantil & $\begin{array}{l}\text { Primer ciclo } \\
\text { de Primaria }\end{array}$ & $\begin{array}{l}\text { Segundo } \\
\text { ciclo de } \\
\text { Primaria }\end{array}$ & $\begin{array}{c}\text { Primer } \\
\text { ciclo de } \\
\text { Secundaria }\end{array}$ & $\begin{array}{l}\text { Segundo } \\
\text { ciclo de } \\
\text { Secundaria }\end{array}$ & Bachillerato \\
\hline \multirow{4}{*}{$\begin{array}{c}\text { EXP. } \\
\text { DID. IX } \\
\text { La } \\
\text { música } \\
\text { en } \\
\text { tiempos } \\
\text { de los } \\
\text { íberos }\end{array}$} & Texto & & & & $\begin{array}{c}\text { Texto en } \\
\text { paridad con } \\
\text { las imágenes. }\end{array}$ & & \\
\hline & Imágenes & & & & $\begin{array}{l}\text { Abundancia } \\
\text { de mapas, } \\
\text { fotografías y } \\
\text { dibujos. }\end{array}$ & & \\
\hline & Vocabulario & & & & $\begin{array}{l}\text { Sencillo y } \\
\text { las palabras } \\
\text { técnicas } \\
\text { limitadas } \\
\text { y bien } \\
\text { explicadas. }\end{array}$ & & \\
\hline & Actividades & & $\begin{array}{l}\text { Relacionar } \\
\text { dibujos con } \\
\text { felchas, } \\
\text { colorear y } \\
\text { diferenciación } \\
\text { de errores. }\end{array}$ & $\begin{array}{l}\text { Cuestionario } \\
\text { verdadero } \\
\text { falso sobre el } \\
\text { texto. }\end{array}$ & & & \\
\hline
\end{tabular}

Tabla 1. Tabla de análisis de actividades que se elaboraron para la clasificación de las Experiencias Didácticas del Museo de "El Cigarrelejo".

En tercer lugar se ha llevado a cabo un balance completo de los datos recogidos para la elaboración de conclusiones, poniendo especial atención a los aspectos positivos y negativos y a la presencia o ausencia de alguna o todas de las competencias básicas según se establece en el Boletín Oficial de la Región de Murcia (BORM, 2007), con el fin de sentar una base lo más sólida posible para la elaboración de unas conclusiones que a la par que críticas, aportaran nuevas líneas de investigación. Esto hizo necesario realizar una búsqueda en el currículo de los contenidos de cada experiencia didáctica para valorar la aproximación en los contenidos, desarrollos, actividades y niveles educativos.

\section{La didáctica en el museo de El Cigarralejo}

\subsection{Materiales didácticos}

El Cigarralejo es un museo de constante actividad que produce periódicamente una gran cantidad de materiales de todo tipo. Por ello se hace necesario descartar los materiales propiamente no didácticos de El Cigarralejo quedando clasificados en tres grupos los materiales didácticos en función del detonante de su preparación:

- Pasatiempos: actividades elaboradas con temática del museo sobre su colección, el mundo ibérico, la arqueología, etc. Enfocadas a Infantil y Primaria.

- Talleres: actividades realizadas durante todo el año aunque habitualmente en verano. Para 
grupos numerosos consistirán en la realización de manualidades con la guía de un profesional. Algunos ejemplos serán: Talla lítica, cestería, cerámica, herrería, mosaico, etc.

- Experiencias didácticas y cuadernos didácticos: materiales en formato de cuadernillo elaborados a partir de temáticas concretas que varían entre las propias del mundo ibérico, como por ejemplo: el guerrero, la mujer, la vegetación, etc., o temáticas arqueológicas, el dibujo arqueológico, incluso de la Prehistoria en general, la talla lítica, y también sobre cada una de las salas del museo y su contenido.

\subsection{Pasatiempos}

Los pasatiempos son el tipo de actividad más numeroso y variable en El Cigarralejo. Esto se debe a la mayor elaboración que tienen las Experiencias Didácticas, que vienen a ser monográficas, y con un nivel demasiado elevado como para que resulte una actividad flexible a que la realicen muchos niveles educativos. Son actividades muy diversas, la mayoría de ellas vienen dedicadas a niveles educativos inferiores, no pasando, por lo general de los primeros cursos de la Educación Secundaria.

Para el nivel Infantil y el primer ciclo de Primaria encontramos pasatiempos que consisten en la elaboración de materiales propios o manualidades, como la fabricación de marionetas, o de caretas; figuras para ser coloreadas siguiendo un patrón numérico, abecedarios con temática ibérica o cuadernillos que contienen una mezcla de todo este tipo de actividades. Normalmente centrados en las manualidades y la resolución de laberintos.

Para el segundo ciclo de Primaria encontramos actividades ya sea de lectura, con cómics y cuentos adaptados a la temática del museo o similar. Todavía predominan las actividades de dibujo, pero tenemos ahora las primeras actividades de relación de conceptos, en su mayoría todavía relación de dibujos y fotografías. También aparecen ahora actividades de desarrollo en pareja o en grupo como por ejemplo: juegos de magia con cartulinas en las que uno de los sujetos memoriza una de las imágenes sin decírsela al otro y este, mediante unas simples preguntas de "sí o no" debe acertar la imagen elegida por descarte sobre las cartulinas, de manera visual para ambos. En grupo hay actividades como la carpeta-teatro, donde a grupos de seis alumnos se les entregará una gran carpeta con un teatro de cartón desplegable en su interior, dotado de figuras y telones deslizantes e información básica para inspirar a los alumnos a elaborar un guión propio que luego deben representar ante sus compañeros.

Finalmente, para los primeros cursos de Educación Secundaria tenemos cuadernillos y cómics específicamente preparados con texto, imágenes y preguntas elaboradas que requieren redacción compleja, son actividades de transición para el otro gran grupo de actividades del museo anteriormente expuesto, las Experiencias didácticas, enfocadas a la Educación Secundaria y niveles superiores.

\subsection{Talleres}

Se desarrollan durante todo el año pero con una especial concentración en verano, momento en el que la afluencia pasa a visitas de grupos de larga duración.

En el museo los talleres realizados se han basado, como en casi todos los museos actuales, en el conocimiento y los contactos del personal del museo. De manera que los talleres y las actividades vienen marcados por los monitores y profesionales que de una u otra forma han tenido relación con el museo y sus trabajadores.

En El Cigarralejo los talleres han sido de diverso tipo, todos en torno a la cultura ibérica. Ha habido desde talleres de caretas, marionetas o móviles para los más pequeños, que recortan, colorean y montan las marionetas o las caretas, según el taller, o también talleres de alfabeto ibérico para los niveles de infantil. También talleres de cerámica o fabricación de mosaicos en los 
que se han elaborado piezas cerámicas de gran calidad a partir de modelos ibéricos expuestos en el museo, horneados en un taller ceramista cercano y pintados y barnizados en el propio museo a lo largo de muchas sesiones de trabajo. Talleres de metalurgia o talla lítica con profesionales y expertos de cada rama, han sido algunos de los talleres más elaborados que se han realizado bajo la organización del museo. Por último, en El Cigarralejo se han realizado excavaciones arqueológicas simuladas para trasmitir la importancia de la arqueología y su método.

En este grupo de actividades tienen cabida todos los grupos de edad de manera que aunque la mayoría de los talleres son concebidos para niños, frecuentemente de Primaria, algunos han sido para grupos mayores incluso para adultos y colectivos de la tercera edad.

Debe constar a favor del museo la gran cantidad y calidad de actividades de ocio ofertadas y amplio espectro social para el que van dirigidas todas.

\subsection{Experiencias didácticas}

Las experiencias didácticas siguen un formato común: cuadernillo en formato $A 4$, en blanco y negro o en color, con una portada llamativa con una fotografía o dibujo característico del tema a tratar, seguidos de un texto de 4 a 8 páginas con abundancia de imágenes, mapas y dibujos, un vocabulario específico del tema y actividades.

Son el tipo de actividad más relacionada con las necesidades que los grupos de la Educación Secundaria pueden albergar. Hemos de recordar que según el curriculum oficial el mundo ibérico estará inserto en el curriculum del primer curso de la Educación Secundaria. Además, por su formato y objetivo serán las preferidas para su realización con la visita de grupos de este nivel educativo.

Comenzaron a realizarse a principios de siglo XXI y se siguen elaborando en la actualidad por los trabajadores y colaboradores del museo.

Su objetivo es impartir un tema en concreto suministrando el contenido, los materiales y las actividades. La temática oscilará siempre entre los temas propios del museo, es decir, todos los específicos de la cultura ibérica, y temas relacionados con la arqueología o la Prehistoria.

El texto viene acompañado de imágenes, dibujos y mapas que se relacionan estrechamente con este. Las palabras específicas vienen resaltadas de manera que llamen la atención del alumno. El lenguaje empleado suele ser sencillo, aunque con excepciones como ya veremos, con construcciones gramaticales muy accesibles para que alumnos de toda la Educación Secundaria incluso cursos finales de la Primaria puedan acceder sin problemas a la elaboración de estos cuadernillos. Sin embargo, pese al lenguaje sencillo, se aprecia en todos ellos una clara tendencia a mantener las palabras propias de la cultura ibérica, pese a que sean muchas veces palabras ajenas al léxico del alumno medio. Para facilitar esto, las palabras vienen resaltadas para que llamen la atención del alumnado y las busque en el vocabulario que viene al final del cuadernillo.

Las actividades son la última parte de cada experiencia didáctica y tienden a ser de tipo relacional, enumerativo y de búsqueda. Sopas de letras; relación de objetos, imágenes y dibujos; enumeración de elementos ibéricos; búsqueda de piezas por el museo; etc.

Aunque la mayoría de las experiencias didácticas son actividades elaboradas con anterioridad a la aparición del concepto de competencia básica en el curriculum, se considera útil establecer la presencia de estas en las actividades en la medida en que muchos de estos materiales siguen empleándose como material didáctico del museo. Las competencias que son atendidas con estas actividades son en la mayoría de los casos las siguientes: la competencia en comunicación lingüística, la competencia matemática, la competencia en el conocimiento y la interacción en el mundo físico y la competencia cultural y artística.

El resto de competencias quedan ausentes de las actividades, como por ejemplo el tratamiento de la información y la competencia digital, en este caso porque las infraestructuras necesarias para el tratamiento y desarrollo de esta competencia son elevadas y la financiación para ello siempre ha sido compleja de obtener. No obstante, y como ya se ha señalado, la ausencia de las otras competencias responde al hecho ya mencionado de que muchos de estos materiales didácticos son 
anteriores a la oficialización del concepto de competencia básica. Por último, la propia configuración del museo influye en la facilidad o dificultad que las competencias elegidas presentan para ser empleadas en la temática del mismo y la dificultad añadida para las otras, menos accesible su relación efectiva con el carácter habitual de un museo.

Las experiencias didácticas ${ }^{3}$ del Museo de El Cigarralejo son las siguientes:

EXP. DID. I. Las excavaciones arqueológicas. Figura 1

EXP. DID. II. La cultura del Argar.

EXP. DID. III. La religiosidad ibérica: el santuario de El Cigarralejo.

EXP. DID. IV. Arqueología experimental. La talla lítica.

EXP. DID. V. El dibujo arqueológico.

EXP. DID. VI. La conservación y restauración del patrimonio arqueológico.

EXP. DID. VII (A). La vegetación en el mundo ibérico. (A) Evidencias arqueológicas. Figura 2, 3,4 y 5

EXP. DID. VII (B). La vegetación en el mundo ibérico. (B) Glosario de plantas.

EXP. DID. VIII. El deporte en Grecia y su influencia en el mundo ibérico. Figura 6

EXP. DID. IX. La música en tiempos de los iberos.

EXP. DID. X. Los hombres de la Prehistoria. Figura 73 y 8

EXP. DID. $X^{4}$. La sociedad ibera a través de la cerámica. Sociedad, actividades económicas y rituales.

EXP. DID. XII. ¿Cómo vivían los íberos? La construcción de sus poblados. Figura 96, 10 y 11

EXP. DID. XIII. La mujer ibérica. Figura 12 y 13

\subsection{Las experiencias didácticas}

De todas las actividades referidas son las experiencias didácticas las únicas que por su formato, su intencionalidad y su desarrollo van dirigidas a los niveles educativos de la Educación Secundaria que son, como ya hemos dicho, los niveles que por curriculum están próximos a la temática propia del museo, esto es, el mundo ibérico.

Como ya hemos descrito más arriba son actividades en formato de cuadernillo individual, con todo el material necesario de trabajo aportado en el propio cuadernillo.

Podemos dividirlas en dos grupos, las experiencias didácticas desarrolladas sobre temáticas específicas de arqueología o Prehistoria, como el dibujo arqueológico, la vegetación prehistórica, etc. $Y$ por otro lado las desarrolladas sobre temática propiamente ibérica, muy en relación con los materiales expuestos en el museo.

A la hora de analizar este grupo de actividades lo haremos desde dos ópticas generales. Por un lado analizaremos la pertinencia de los materiales, las actividades y los contenidos de cada una de ellas en relación al nivel educativo proyectado, a las competencias básicas si procede, a la coherencia interna, etc. Y por otro lado entraremos a analizar el desarrollo del currículo oficial que hacen estas actividades.

Son en definitiva actividades de elaboración compleja, que requieren texto e imágenes para formar un discurso coherente sobre temática de una gran complejidad, en algunos casos extrema. Si bien se puede observar que los contenidos desarrollados son de una riqueza y un rigor elevados, con vocabularios acordes a esta riqueza de los contenidos, las actividades sin embargo se quedan en muchos casos en la superficie de la ambiciosa apuesta temática de casi todas las experiencias didácticas.

Contenidos y actividades quedan separados por una gran brecha en lo que a nivel educativo se refiere. Todas las experiencias didácticas están originalmente pensadas para niveles de Educación Secundaria, tanto por su complejidad como por ser la Educación Secundaria el nivel educativo

3 En adelante EXP. DID.

4 No es una errata. El museo editó dos cuadernillos con la misma numeración. 
donde el curriculum establece el mundo ibérico. Sin embargo, los textos son de una riqueza tal y de una variedad léxica tan elevada que probablemente no sean adecuados para el primer ciclo de la Educación Secundaria, quedando en el límite de los asumibles para los actuales estudiantes de tercero y cuarto de la Educación Secundaria. Por otra parte, las actividades quedan completamente distantes de los niveles educativos planteados, no ya en el currículo, como veremos más adelante, sino de los propios contenidos propuestos. Muchas de las actividades, que desglosaremos a continuación, son propias del primer ciclo de Primaria, algunas de ellas de Infantil, y sin embargo vienen acompañadas de textos y glosarios propios de Bachillerato.

En las siguientes líneas analizaremos las experiencias didácticas una a una estableciendo para cada una de las partes que las forman la pertinencia en los contenidos, las actividades, el desarrollo del currículo, etc.

a. EXP. DID. I, "Las excavaciones arqueológicas" (Page y Acosta, 2002) (Figura 1)

El texto se centra en justificar el papel del arqueólogo y definirlo, para luego pasar a describir su trabajo con un nivel muy alto de detalle. De esta forma se describen métodos, ciencias auxiliares, pasos a seguir en determinadas fases de la excavación, etc. El vocabulario empleado es de un nivel alto aunque siempre dentro de la comprensión de un alumno de Educación Secundaria. El vocabulario específico viene resaltado y sin embargo no hay ningún tipo de glosario donde pueda consultarse en el momento el significado de palabras como palinología, estrato o topografía. Los dibujos que acompañan al texto son idóneos, añadiendo claridad al conjunto.

Las actividades propuestas son cuestionarios sobre lo aprendido de manera que en caso de dificultades el cuadernillo puede ser consultado fácilmente de forma que lo que no ha quedado asentado en un primer momento puede ahora consolidarse. Los tipos de actividades son; cuestionarios de preguntas cortas, colocación en orden de una secuencia estratigráfica de dibujos de diferentes épocas, etc.

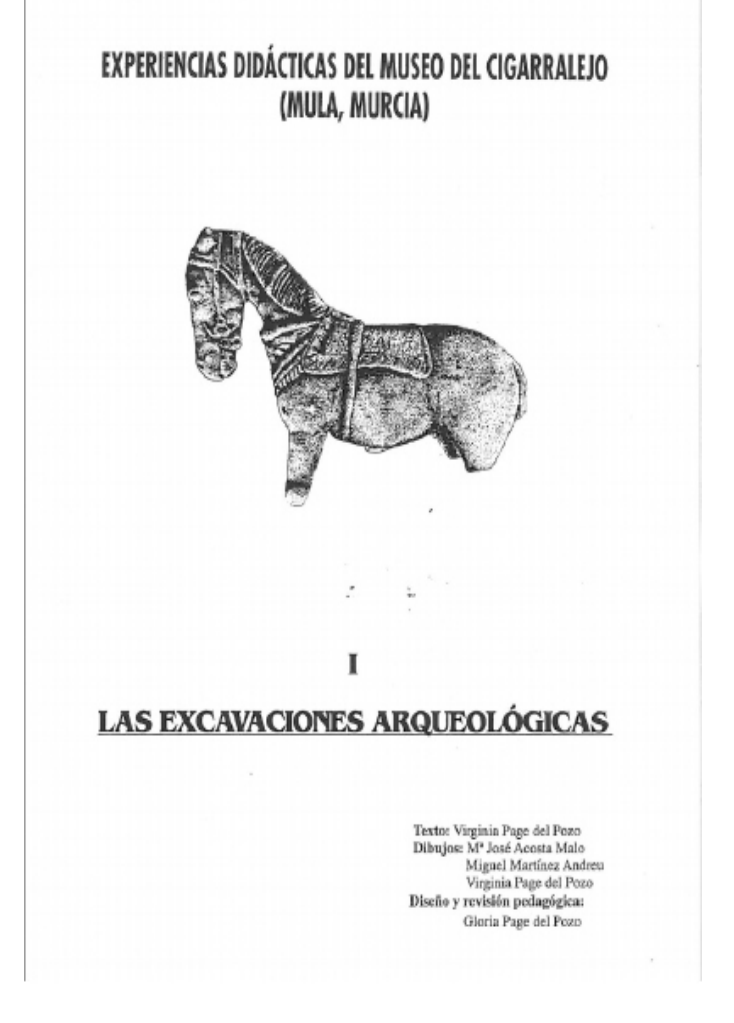

Figura 1: Portada de la Experiencia didáctica número 1. (Page y Acosta, 2002) 
b. EXP. DID. II, "La cultura del Argar" (Page y Acosta, 2002)

El texto es sencillo pese al gran nivel de detalle en aspectos cotidianos de la cultura del Argar, de manera que la comprensión del texto no viene condicionada por la edad sino solo por el volumen de vocabulario conocido que puede ser consultado al final de la actividad en el glosario anexo.

Las actividades serán ordenar una lista de dibujos sobre procesos técnicos argáricos y cuestionarios sobre la cultura del Argar, siempre de respuesta corta. Además, al final, adjunta pasatiempos para un nivel inferior, cursos iniciales de la Primaria incluso infantil, laberintos, coloreado de dibujos y búsqueda de errores.

Los pasatiempos que se adjuntan al final de la experiencia didáctica están claramente enfocados para niveles inferiores, probablemente de inicios de la Educación Primaria, con la intención posible de flexibilizar el cuadernillo para más niveles educativos.

c. EXP. DID. III, "La religiosidad ibérica: El Santuario de El Cigarralejo (Page y Acosta, 2002)

El texto de esta actividad es más complejo que el de las anteriores, aunque permanezca en el límite de lo accesible para alumnos de Educación Secundaria. El uso de vocabulario específico continua como "marca de la casa" aunque sin excederse notablemente y bien señalado en el texto para su búsqueda, si procede, en el glosario anexo al final de la actividad.

Las actividades para la Educación Secundaria en este cuaderno quedan limitadas a un único cuestionario de respuesta breve sobre lo aprendido.

Al final adjunta también pasatiempos en torno a la localización de errores, diferenciación de objetos y laberintos.

d. EXP. DID. IV, “Arqueología experimental. La talla lítica” (Marín de Espinosa, 2002)

El texto introduce al alumno en el conocimiento del porqué de la talla lítica en Prehistoria, su desarrollo y la utilidad de la misma para el estudio de las sociedades prehistóricas, para adentrarse en el breve desarrollo de las fases de la Prehistoria, desde el paleolítico hasta las edades de los metales. El vocabulario resaltado es muy complejo, incluyendo términos específicos como raedera, musteriense, técnica laminar o denticulado y el texto general emplea léxico fuera del alcance de la mayoría de los alumnos de Educación Secundaria. Las actividades sin embargo serán tres de ordenación de dibujos de elaboración de piezas líticas, vistas durante la lectura del tema, y una sopa de letras para buscar términos desarrollados durante la actividad, todos ellos propios de los cursos de Primaria.

e. EXP. DID. V. “El dibujo arqueológico" (Page y Acosta, 2002)

Nos volvemos a encontrar con una temática muy específica, de corte muy técnico, en desconexión con los contenidos de la Educación Secundaria. El texto es de un perfil alto, probablemente en el límite de ser apto para los últimos cursos de la Educación Secundaria. Palabras como perfilador, cotas o pie de rey quedan en el límite. Las actividades, sin embargo serán una sopa de letras con los términos aprendidos, propia del segundo ciclo de Primaria, unir números en orden para forma un dibujo, ejercicio adecuado para el primer ciclo de Primaria y finalmente hallar entre seis dibujos de una jarrita las dos que son iguales, actividad propia también de los primeros cursos de Primaria. De nuevo las actividades, el texto y el vocabulario quedan muy distantes entre sí.

f. EXP. DID. VI. "La conservación y restauración del patrimonio arqueológico" (Buendía, Acosta y Page, 2002)

Esta actividad es un ejemplo claro de esta primera etapa de Experiencias Didácticas del Museo de El Cigarralejo, el nivel del texto es muy elevado, si lo analizamos desde el punto de vista del vocabulario específico empleado, y sin embargo, el nivel no es tan alto si atendemos a la comprensión lectora del alumnado de $1 .^{\circ}$ de la Educación Secundaria. De esta forma el texto y el glosario que se adjunta al final permitirán al alumno una comprensión total del texto y una 
asimilación de conocimiento muy ambiciosa.

Las actividades son la relación de objetos con funciones, y un cuestionario de repaso de los principales dogmas de la restauración y la conservación aprendidos.

Al final adjunta una serie de pasatiempos para niveles inferiores. Tendremos un dibujo recortable para pegarlo en el orden correcto y una sopa de letras sobre términos específicos del tema.

g. EXP. DID. VII. (A) y (B) "La vegetación en el mundo ibérico (A). Evidencias arqueológicas" (Casado y Page, 2004) y "La vegetación en el mundo ibérico (B). Glosario de plantas" (Casado, Martínez, y Page, 2004) (Figuras 2, 3, 4 y 5)

Dividida en dos cuadernillos, uno dedicado a las "Evidencias arqueológicas", y otro "Glosario de plantas". En el texto se emplean nombres técnicos de plantas y elementos del mundo ibérico y palabras que requieren una cultura mayor a la habitual entre los estudiantes de Educación Secundaria tales como etnografía, inmutable, orografía, etc. Dibujos, imágenes y referencias son también muy específicos, llegando a mencionarse tumbas del yacimiento de El Cigarralejo y los estudios científicos realizados sobre ellas, polínicos, antracoanálisis, etc. El volumen $B$ de este cuadernillo es un glosario de las plantas propias del periodo ibérico que incluye definiciones y términos científicos, propios, en el mejor de los casos, de un segundo de Bachillerato. Por el contrario las actividades serán laberintos, localización de elementos fuera de lugar en un dibujo y hallar las diferencias entre dos dibujos similares. Todas ellas propias de Infantil y los primeros cursos de Primaria.

\section{h. EXP. DID. VIII. "El deporte en Grecia y su influencia en el mundo ibérico" (Serrano y Page,} 2004) (Figura 6)

Quedará un poco más cerca del currículo oficial, en cuanto a temática general, aunque por lo particular del tema elegido volverá a situarse muy lejos de lo deseado. De nuevo, texto y vocabulario se combinan para alejar completamente el contenido de lo propio de las edades para las que está proyectado. La referencia continua a elementos y términos específicos separan el texto de su comprensión por parte de alumnos de Educación Secundaria. Pedotriba, estrígilo, alipta, etc., están en conjunto fuera del alcance de estos alumnos. Por el contrario las actividades serán: una sopa de letras, propia como mucho del segundo ciclo de Primaria, y una serie de preguntas sobre la comprensión del texto, apta para los primeros curso de la Educación Secundaria.

\section{i. EXP.DID. IX, "La música en tiempos de los iberos" (Aguado y Castelo, 2006)}

Este cuadernillo es también sobre temática ibérica y se ciñe en mayor medida a los contenidos impuestos por el currículo oficial. Aunque el tema es muy específico, texto, imágenes y vocabulario son ahora más aptos que en anteriores experiencias didácticas para los cursos de la Educación Secundaria. El lenguaje ahora es más sencillo y el narrador se dirige al lector con frecuencia haciendo el texto mucho más cercano y sencillo de comprender. El vocabulario, aunque muy específico, está perfectamente aclarado durante la lectura, además de desarrollado en el vocabulario final por lo que no escapa en principio a las capacidades de comprensión de los alumnos de los cursos iniciales de la Educación Secundaria. Sin embargo las actividades serán para niveles inferiores. La primera, de verdadero y falso es la única que se podría intentar hacer pasar a un curso de $1 .^{\circ}$ de la Educación Secundaria, pero las siguientes, de unir figuras con flechas, diferenciar figuras por su forma o colorear un cuadro siguiendo una leyenda de figuras son actividades propias del primer ciclo de Primaria.

j. EXP.DID. X. "La sociedad ibera a través de la cerámica. Sociedad, actividades económicas y rituales" (Jiménez, 2008)

El texto y las imágenes de esta actividad son probablemente las más cercanas a los objetivos del currículo oficial, junta los conocimientos y objetivos didácticos con la metodología científica. 


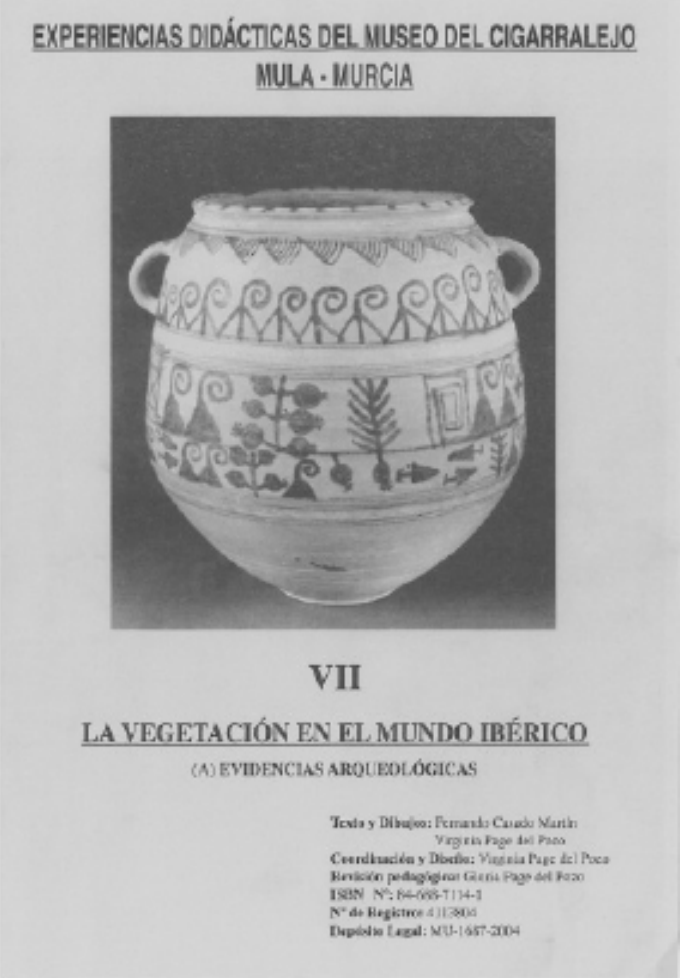

Figura 2: Portada de la Experiencia didáctica número 7. (Casado y Page, 2004)
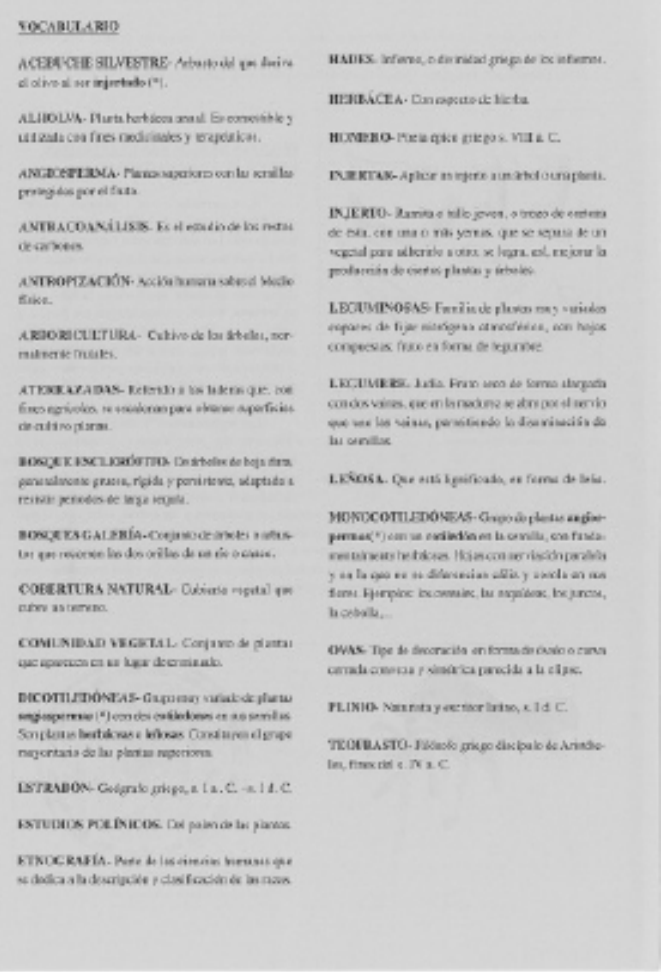

Figura 4: Vocabulario de la Experiencia didáctica número 7. (Casado y Page, 2004)

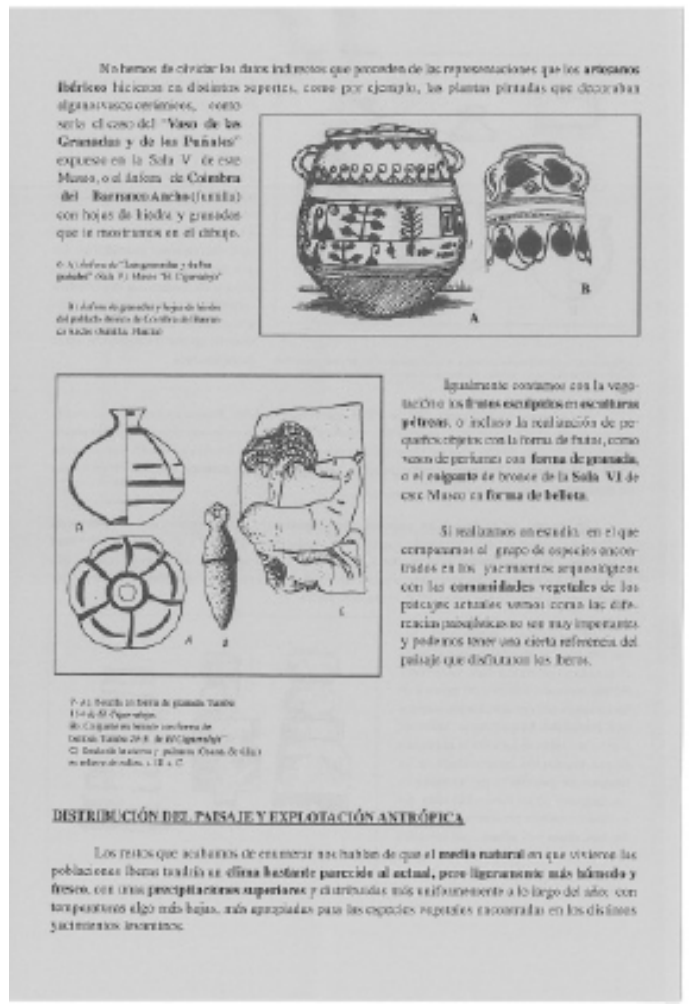

Figura 3: Parte teórica de la Experiencia didáctica número 7. (Casado y Page, 2004)

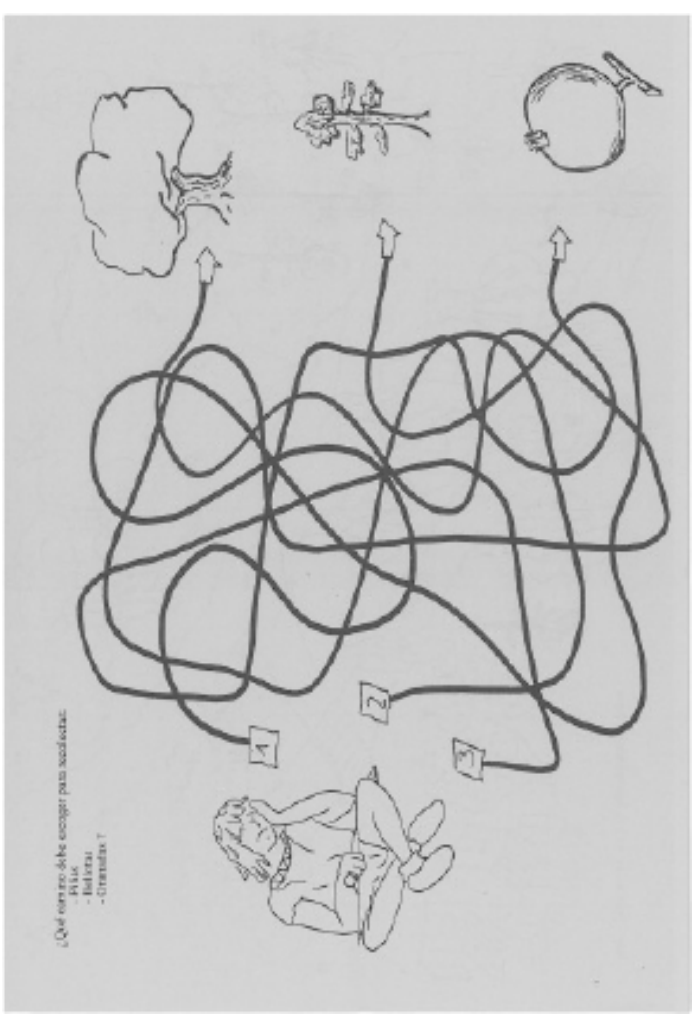

Figura 5: Actividades de la Experiencia didáctica número 7. (Casado y Page, 2004) 
EXPERIENCIAS DIDÁCTICAS DEL MUSEO DEL CIGARRALEJO MULA. MURCIA

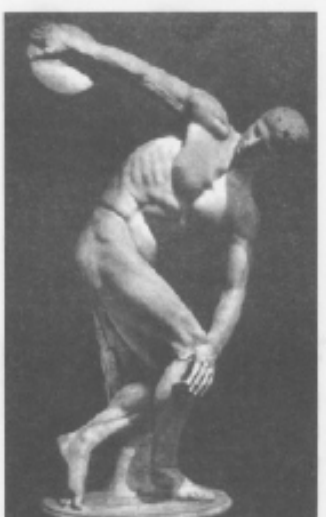

VIII

EL DEPORTE EN GRECIA Y SU INFLUENCIA EN EL MUNDO IBÉRICO

Teatec Paricis Serson Mryoul

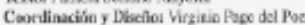

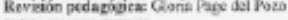
BDNerstoss-

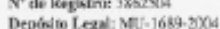

Figura 6: Portada de la Experiencia didáctica número 8. (Serrano y Page, 2004)

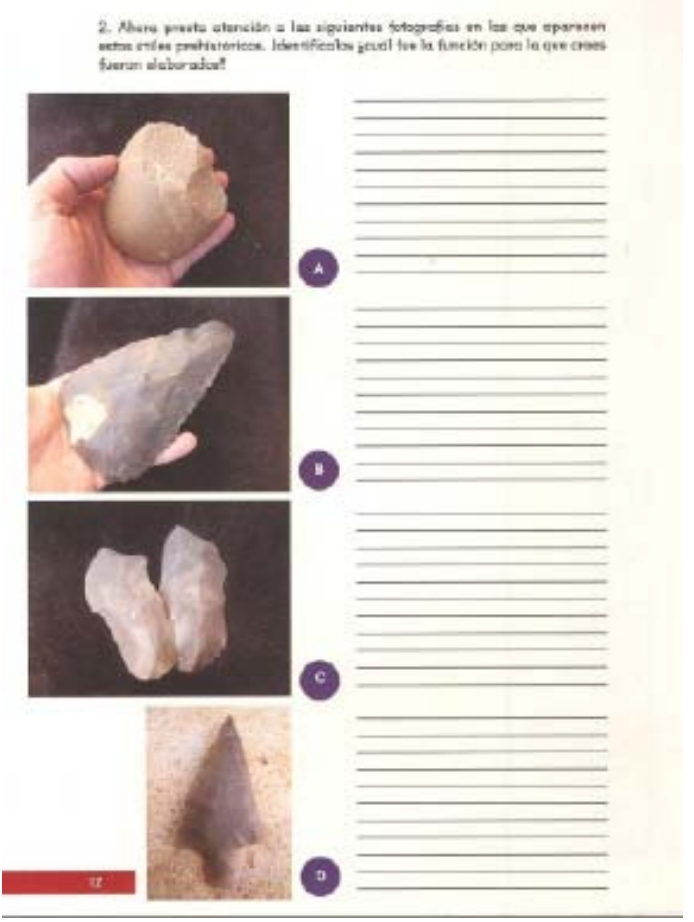

Figura 8: Actividades de la Experiencia didáctica número 10. (Marín, 2006)
Experiencias didácticas del Museo de Arte Ibérico "El Cigarralejo" (Mula. Murcia)
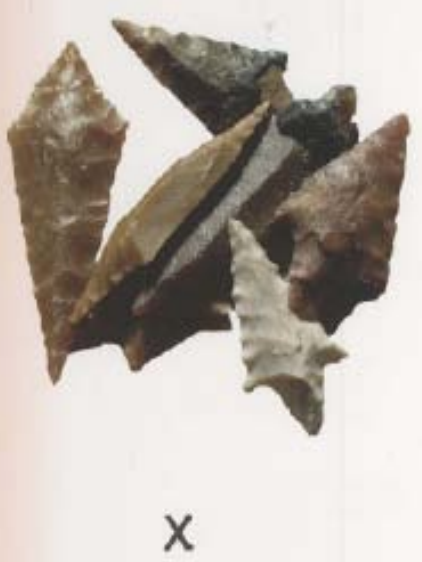

Los hombres de la Prehistoria

Figura 7: Portada de la Experiencia didáctica número 10. (Marín, 2006)

\section{Experiencias Didácticas del Museo "El Cigarralejo" Mula - Murcia}

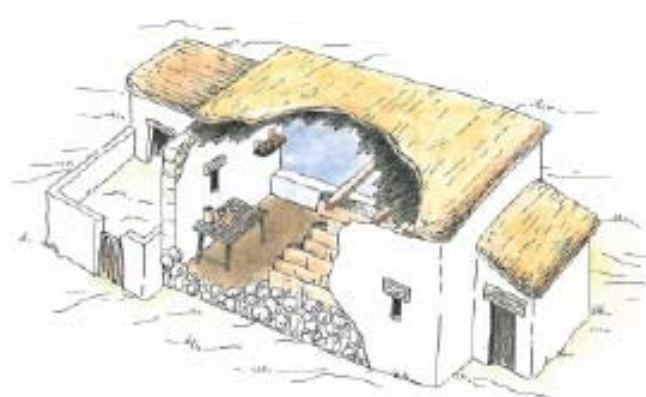

\section{XII}

\section{¿CÓMO VIVÍAN LOS ÍBEROS?}

La construcción de sus poblados

Figura 9: Portada de la Experiencia didáctica número 12. (Arias, 2008) 


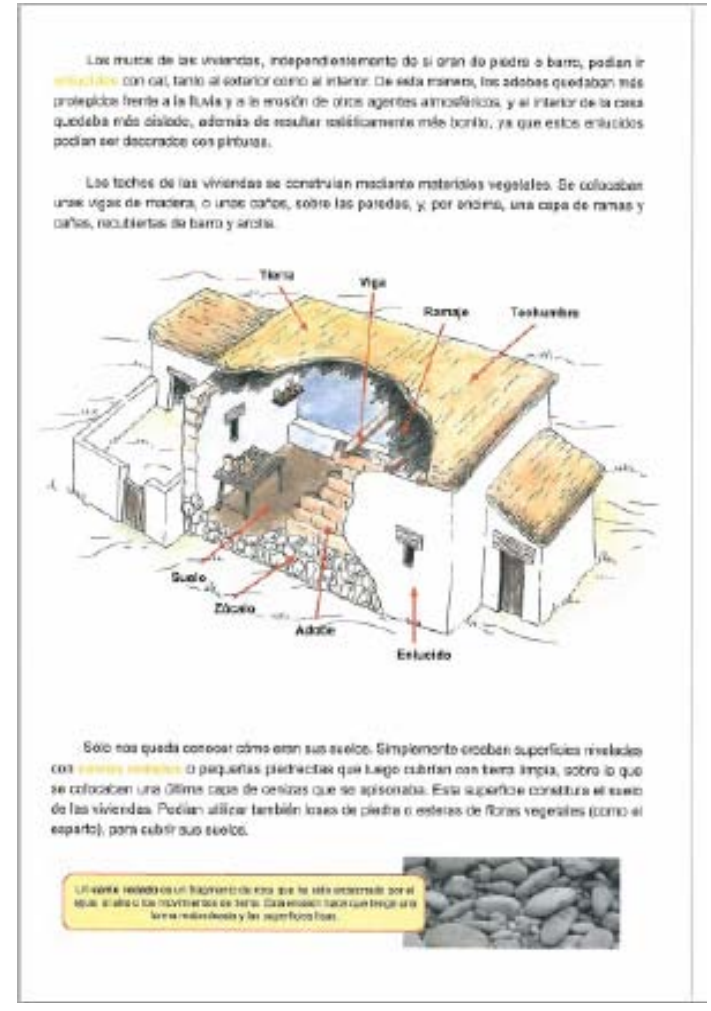

Figura 10: Teoría de la Experiencia didáctica número 12. (Arias, 2008)

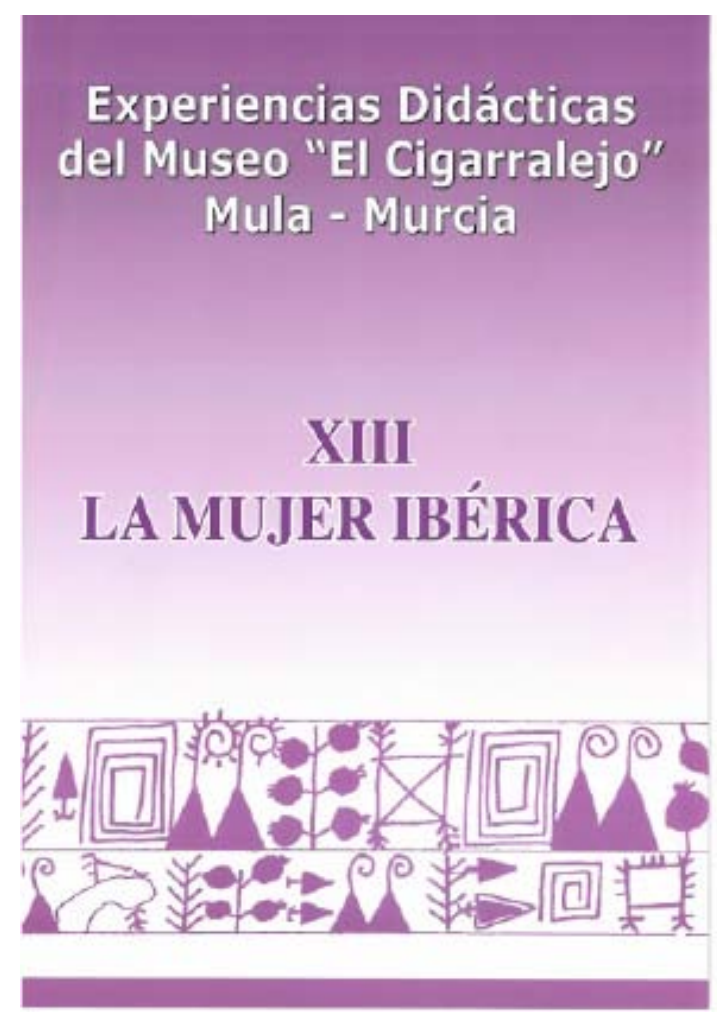

Figura 12: Portada de la Experiencia didáctica número 13. (Gualda, 2009)

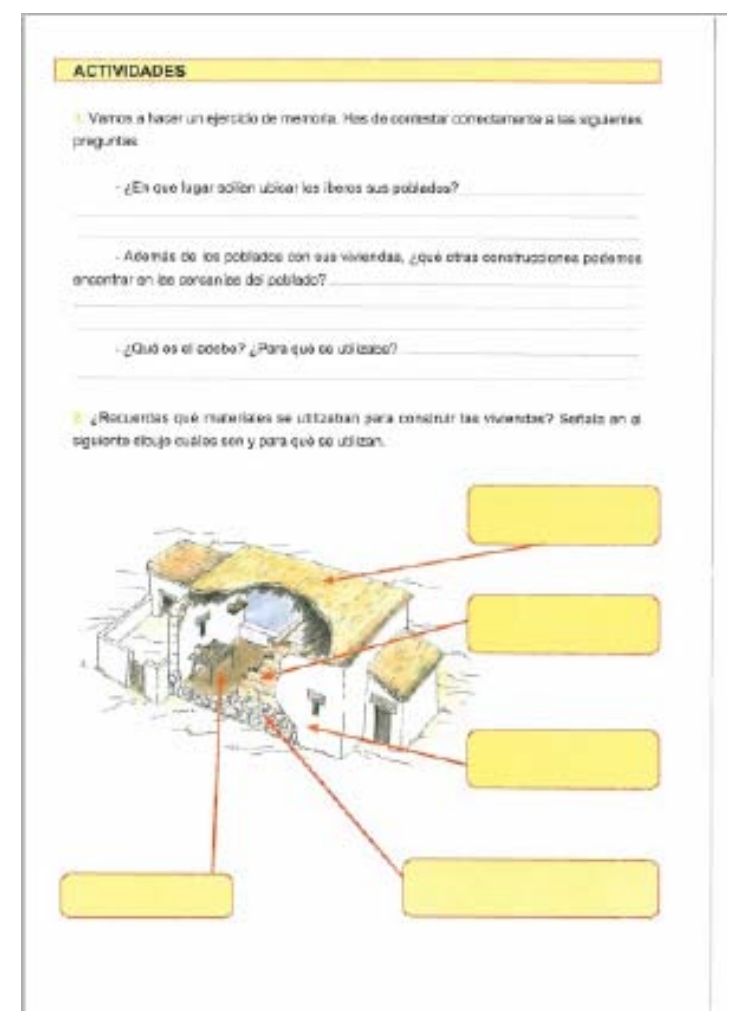

Figura 11: Actividades de la Experiencia didáctica número 12. (Arias, 2008)

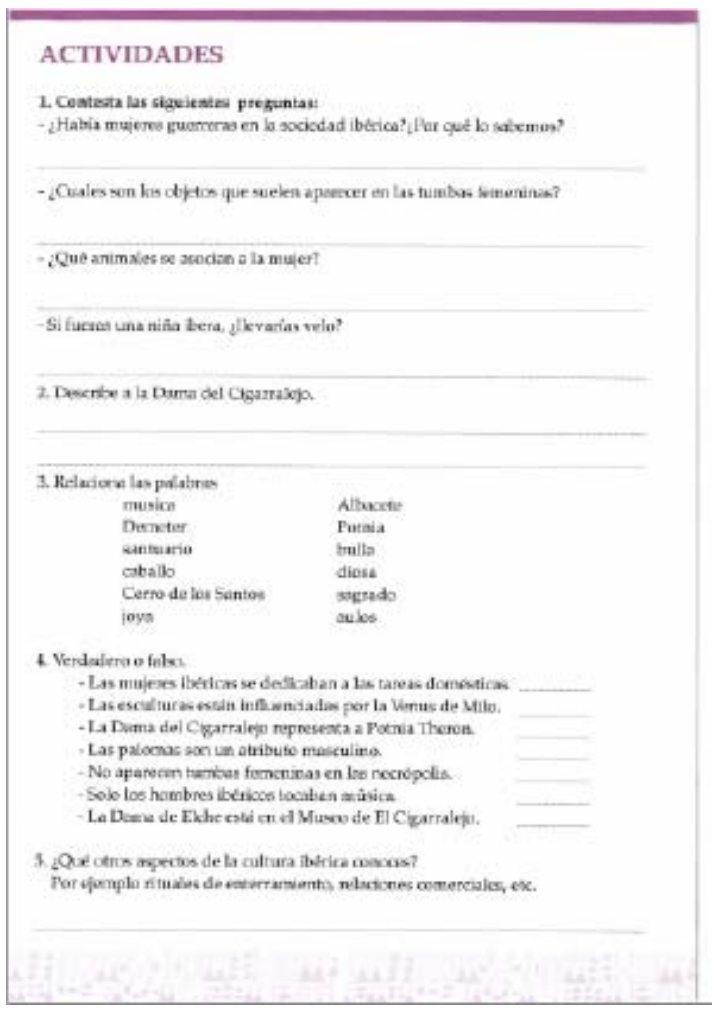

Figura 13: Actividades de la Experiencia didáctica número 13. (Gualda, 2009) 
Por el lado científico se explicará cómo se conoce a los íberos a través de una de sus principales fuentes de estudio, la cerámica. Y por otro lado se desarrollará la sociedad ibérica en términos que los alumnos de $1 .^{\circ}$ de la Educación Secundaria sean capaces de comprender, asimilar y aprender correctamente, atendiendo a aspectos comunes y cotidianos como la ganadería y la agricultura, la guerra, el comercio, la artesanía, etc. El vocabulario es breve pero preciso y no se centra solo en términos científicos sino también en palabras más habituales pero aun difíciles para estos niveles, como urbanismo o patriarcal. Las actividades sin embargo serán para cursos iniciales de Primaria e Infantil, consistiendo en elaborar dibujos siguiendo un ejemplo, diferenciar en dibujos ibéricos elementos ajenos y un laberinto.

\section{k. EXP.DID. X. "Los hombres de la Prehistoria"s (Marín, 2006) (Figuras 7 y 8)}

La actividad se centra en explicar brevemente los periodos en los que está dividida la Prehistoria a través de la industria lítica de cada periodo. Así mismo, se va describiendo esta industria y los principales elementos que la componen y cómo a través de ella se puede estudiar la vida cotidiana de estas sociedades del pasado. Las actividades consisten en fotografías a ordenar de piezas de elaboración de utillaje óseo y lítico, comentario-definición de cuatro fotografías de elementos líticos previamente explicados y relación de materiales con el periodo al que pertenecen.

I. EXP. DID. XII. “¿Cómo vivían los íberos? La construcción de sus poblados” (Arias, 2008) Figura 9,10 y 11

La experiencia didáctica explica cómo identificar los poblados ibéricos, en su morfología, su distribución y sus funciones principales más destacas en el campo económico, militar y religioso. El vocabulario empleado es muy similar al de los libros de texto de la Educación Secundaria, siendo claro, simple y conciso. Es específico pero sobre elementos cotidianos. Las actividades son preguntas cortas sobre los contenidos impartidos.

m. EXP. DID. XIII. “La mujer ibérica” (Gualda, 2009) (Figuras 12 y 13)

La temática de esta experiencia didáctica es difícil de asimilar a los contenidos del currículo oficial debido a su especificidad. Además, texto e imágenes componen una narración de gran nivel, propia de niveles de Bachillerato o cursos finales de la Educación Secundaria. Las actividades son preguntas cortas, de descripción en su mayoría, relación de conceptos y verdadero o falso.

\subsection{Conclusiones del análisis}

De todas las experiencias didácticas se puede extraer inicialmente una sencilla conclusión: el nivel de los materiales, textos, mapas, etc.; tiende por lo general a estar muy por encima del nivel de las actividades que los acompañan, siendo la diferencia a veces tan tremenda como pasar de cursos iniciales de Primaria a Bachillerato. Por otra parte el nivel curricular de los contenidos está enfocado para $1 .^{\circ}$ de la Educación Secundaria, tal y como se establece en el currículo oficial de Educación de la Región de Murcia para la materia de Ciencias sociales, Geografía e Historia (BORM, 2007), lo que se suma a la enorme divergencia que hay entre los materiales, los contenidos y su evaluación. La gran calidad de los materiales en su conjunto y cada parte por separado contrasta con el desfase de unos respecto a otros y sobre todo respecto del curriculum oficial.

No obstante, conforme las experiencias didácticas son más recientes, el nivel de los textos y de las actividades se va equiparando entre sí y acercándose a los niveles establecidos por el curriculum oficial.

Pese a todo, las experiencias didácticas resultan de una extraordinaria calidad, tanto por su rigor científico, como por su calidad material así como por los cortes transversales que realizan a la parte correspondiente del currículo.

5 No es un error. Se publicaron dos cuadernillos diferentes con el mismo número. 
La principal crítica viene por el hecho de que, pese a los años transcurridos, las actividades propuestas son siempre del mismo tipo, configurando cuadernillos y ejercicios sobre enfoques muy teóricos, en los que el interés del alumno es crucial para su realización con éxito y donde la existencia de una colección excelente de materiales de la cultura ibérica no es vinculada como se merece a las actividades.

De esta forma, un alumno podría llevarse los cuadernillos a casa, y realizarlos allí sin necesidad ninguna de haber visto el museo y sus colecciones. Esta circunstancia es a la vez crítica y alabanza de los materiales. Alabanza porque son suficientemente completos como para constituirse en una unidad autónoma de enseñanza para cualquier alumno que los trabaje; y crítica, porque al no vincular las actividades a la visita comprensiva del museo y sus materiales pierden buena parte del sentido de sus objetivos.

Como dice Santacana (1998) hay que tener en cuenta que las actividades que depositan casi exclusivamente su éxito o su fracaso en el interés medio del alumnado tienden a fracasar en gran medida frente a las actividades que implican a este en su propio aprendizaje como actor principal. Una actividad que relacione directamente al sujeto del aprendizaje con todo el procesoserá una actividad con mayores posibilidades de éxito y cuyos conocimientos aprendidos serán de mayor calidad.

\section{Reflexiones finales}

Los dos grandes caballos de batalla sobre los que se ha cimentado el análisis de las actividades del museo han sido: la adecuación de los contenidos de las actividades del museo a los contenidos del curriculum oficial para los niveles propios de la temática tratada, y la coordinación de las diferentes partes de cada actividad al nivel educativo en cuestión.

En primer lugar las Experiencias Didácticas del Museo se ciñen a los niveles educativos del curriculum oficial solo en contadas ocasiones, ya puede ser en la primera etapa de las publicaciones, o en los últimos años de estas. Esto es un error. Si se quiere relacionar el Museo con los centros de la Educación Secundaria, y convertir las salas del museo en una prolongación activa de las aulas, es necesario que los contenidos ofertados a través de las Experiencias Didácticas del Museo no solo sean acordes al nivel educativo de los alumnos recibidos sino que los contenidos correspondan a los del curriculum oficial y la visita al museo complemente con éxito a la docencia ordinaria. Las actividades deben servir tanto a los alumnos como a los docentes puesto que parte del éxito de la actividad realizada en el Museo vendrá condicionado por la complementación de las actividades realizadas con la docencia de las aulas.

En segundo lugar es necesario adecuar de forma más activa las actividades al nivel educativo concreto del curriculum oficial que trata la cultura ibérica, $1 .^{\circ}$ de la Educación Secundaria. Y paralelamente, también será necesario adecuar a cada elemento de cada actividad al nivel educativo al que va dirigido, poniendo especial atención en homogeneizar texto, vocabulario y actividades para cada actividad, y evitar así la desconexión de cada parte con su objetivo primordial. En esta línea es tolerable cierta flexibilidad al establecer la pertenencia a un nivel educativo concreto de cada actividad, puesto que la temática influye directamente en las actividades y en su contenido, sin embargo, no es posible que los ejercicios, el texto y el vocabulario estén completamente desconectados, máxime cuando esta separación viene por el nivel educativo de cada parte, que es en ocasiones muy distante.

Dicho todo esto se ha de añadir que las Experiencias Didácticas del Museo de El Cigarralejo son actividades de gran calidad científica, y en los casos que las Experiencias Didácticas se adecuan a los contenidos del curriculum oficial y al nivel educativo son de una pertinencia educadora formidable. Sin embargo, adolecen en general de una desconexión severa con los materiales expuestos, de manera que el alumnado que realiza las Experiencias Didácticas no tiene la necesidad, en general, de estar físicamente en el Museo, en muchos casos ni siquiera tiene porque conocer el contenido de su colección. Como ya se ha señalado, esta característica supone a la vez una fortaleza y 
una debilidad de las Experiencias Didácticas. Fortaleza en la medida que permite al alumno con interés ampliar y profundizar en su conocimiento del Museo, pero también debilidad, al no implicarle directamente con el aprendizaje, obligando así al alumno a asumir un interés y una participación inicial mucho mayor de la habitual entre el alumnado medio de estos niveles.

No hace demasiado tiempo que los museos eran lugares donde se situaban exposiciones sobre diversos temas como resultado del trabajo de científicos, historiadores, etc. Hoy en día esto ha cambiado y en buena medida continua cambiando pues ahora los museos son lugares donde también se pretende que se conozca el trabajo que ha dado lugar a los materiales y el discurso expositivo. Poco a poco, la visita al museo vuelve más cómplice al visitante y lo situa en un plano de igualdad. De la misma forma ahora se le otorga el rol de constructor de ideas y aparece el plano didáctico como rector de la situación y del conjunto. Finalmente, el éxito de una visita al museo pasa por crear un vínculo entre el visitante y la exposición, un vínculo, que en el caso de alumnos y alumnas de la Educación Secundaria forje una nueva relación basada en el ocio y en el aprendizaje.

En definitiva, es muy importante en la actualidad que los museos, guardianes del pasado y referentes del presente, estén en sintonía con la educación que la sociedad demanda a diario para sí misma, y sobre todo sirvan como herramienta de trabajo, como lugar de ocio y como prolongación de las aulas de los centros escolares. Alumnado y profesorado deben encontrar en los Museos herramientas que no tengan en sus aulas y que complementen la formación de una forma siempre actualizada con las necesidades tanto de docentes como de discentes. El Museo estará entonces perfectamente adaptado a las necesidades de la sociedad y un paso por delante de esta en su labor educativa.

\section{Bibliografía}

Aguado Molina, M., y Castelo Ruano, R. (2006). La música en tiempos de los íberos. Mula: Museo El Cigarralejo.

Arias Ferrer, L. (2008). ¿Cómo vivían los íberos? La construcción de sus poblados. Mula: Museo de El Cigarralejo.

Arias Ferrer, L., Egea Vivancos, A., y Pernas García, S. (2012). El juego como herramienta educativa para el aprendizaje de la Historia: Los Amos del Foro. En O. Fontal Merillas, P. Ballesteros Valladares, y M. Domingo Fominaya, I Congreso Internacional de Educación Patrimonial. Mirando a Europa: estado de la cuestión y perspectivas de futuro (pp. 182-191). Madrid: IPCE, OEPE.

Asensio, M., y Pol, E. (2003). Aprender en el museo. Íber, 36.1, 62-78.

Ballart, J. (1997). El patrimonio histórico y arqueológico: valor y uso. Barcelona: Ariel.

Ballart, J. (2007). Manual de museos. Madrid: Síntesis.

Decreto número 291/2007, de 14 de septiembre, por el que se establece el currículo de Educación Secundaria Obligatoria en la Comunidad Autónoma de la Región de Murcia Región de Murcia (2007). En Boletín Oficial de la Región de Murcia, N. ${ }^{\circ} 221$. Región de Murcia.

Buendía Ortuño, M., Acosta Malo, M. J., y Page del Pozo, G. (2002). La conservación y restauración del patrimonio arqueológico. Mula: Museo de El Cigarralejo.

Casado Martín, F., Martínez Gómez, A., y Page del Pozo, V. (2004). La vegetación en el mundo ibérico (B). Glosario de plantas. Mula: Museo El Cigarralejo.

Casado Martín, F., Page del Pozo, V., y Page del Pozo, G. (2004). La vegetación en el mundo ibérico. (A) Evidencias arqueológicas. Mula: Museo El Cigarralejo.

Coca Jiménez, P. (2010). EI Discurso Expositivo del Museo desde Contextos Pedagógicos. Arterapia: Papeles de arterapia y educación artística para la inclusión social, 5, 211-221.

Domínguez Arranz, A. (2003). Actas de los XIII Cursos Monográficos sobre Patrimonio Histórico. La museología participativa. La función de los educadores de museo. Reinosa, 99-117.

Estepa Giménez, J. D. (2001). Museo y patrimonio en la didáctica de las ciencias sociales. Huelva: 
Universidad de Huelva.

Fernández Cervantes, M. (2003). Los museos: espacios de cultura, espacios de aprendizaje. Íber, $36,1$.

Fontal, O. (2010). La investigación universitaria en Didáctica del Patrimonio: aportaciones desde la Didáctica de la Expresión Plástica. /l Congrés Internacional de Didàctiques. 267.

García, P. y Martín, P. (2009). La ciudad y el patrimonio histórico como recursos educativos. Gijón: Íber.

Gualda Bernal, R. M. (2009). XIII La Mujer ibérica. En V. Page del Pozo, Experiencias didácticas del museo El Cigarralejo. Mula: Museo El Cigarralejo.

Hernández Cardona, F. X. (1998). Museología y didáctica. Consideraciones epistemológicas. Íber, 15, 14-22.

Hernández Hernández, F. (2002). El patrimonio cultural: la memoria recuperada. Gijón: Trea.

Jiménez Martínez, A. (2008). La sociedad ibera a través de la cerámica. Sociedad, actividades económicas y rituales. Mula: Museo El Cigarralejo.

Marín de Espinosa Sánchez, J. A. (2002). Arqueología experimental. La talla lítica. Mula: Museo El Cigarralejo.

Marín Espinosa Sánchez, J. (2006). Los hombres de la Prehistoria. Mula: Museo El Cigarralejo.

Page del Pozo, V. (2003). El Cigarralejo Museo Monográfico de Arte Ibérico. Mula: Tabularium.

Page del Pozo, V., Acosta Malo, M. J., y Page del Pozo, G. (2002a). El dibujo arqueológico. Mula: Victoria de Mula.

Page del Pozo, V., Acosta Malo, M. J., y Page del Pozo, G. (2002b). La religiosidad ibérica: el santuario de El Cigarralejo. Mula: Museo de El Cigarralejo.

Page del Pozo, V., Acosta Malo, M. J., y Page del Pozo, G. (2002c). Las excavaciones arqueológicas. En V. Page del Pozo, Experiencias didácticas del Museo de El Cigarralejo. Mula: Museo de El Cigarralejo.

Page del Pozo, V., Acosta Malo, M., y Page del Pozo, G. (2002d). La cultura del Argar. Mula: Museo de El Cigarralejo.

Pozo del, J. M. (2012). ¿Crisis de la cultura? Her\&Mus, 11, 8-14.

Piaget, J. (1983). La psicología de la inteligencia. Barcelona: Crítica.

Pujolàs Maset, P. (20 de noviembre de 2003). El aprendizaje cooperativo: algunas ideas prácticas. Recuperado el 20 de julio de 2013, de ciencias: http://www.deciencias.net/convivir/1. documentacion/D.cooperativo/AC_Algunasideaspracticas_Pujolas_21p.pdf

Santacana Mestre, J. (1998). Museos, ¿al servicio de quién? íber. 15, 2-4.

Santacana Mestre, J., y Serrat Antolí, N. (2001). Una reflexión sobre conceptos históricos aprendidos a través del juego. Íber, 30, 37-45.

Santacana Mestre, J. y Serrat Antolí, N. (2005). Museografía didáctica. Barcelona: Ariel.

Santacana Mestre, J., y Martín Piñol, C. (2010). Manual de museografía interactiva. Gijón: Trea.

Sancatana Mestre, J. (2012). Museos y dinero: un binomio difícil de resolver. Her\&Mus, 11, 15-23.

Serrano Mayoral, P., Page del Pozo, V., y Page del Pozo, G. (2004). El deporte en Grecia y su influencia en el mundo ibérico. Mula: Museo El Cigarralejo.

Serrat Antolí, N. (2005). Acciones didácticas y de difusión en museos y centros de interpretación. En Santacana Mestre, J. (ed.). Museografía interactiva. Barcelona: Ariel.

Suarez, M.A., Gutierrez, S., Calaf, R., San Fabían, J. L. (2013). La evaluación de la acción educativa museal: una herramienta para el análisis cualitativo. Clío, 39. Recuperado de http://clio.rediris. es/n39/articulos/calaf

Tejera Pinilla, C. (2012). La cibermuseografía didáctica como contexto educativo para la enseñanza y el aprendizaje del patrimonio. Estudio de páginas web educativas de museos virtuales de arte. Recuperado de http://www.educacion.gob.es/teseo/imprimirFicheroTesis.do?fichero=42105

Tryphon, A., y Vonèche, J. (2000). Piaget-Vygotsky: la génesis social del pensamiento. Buenos Aires: Paidós.

Tugores, F. P. (2006). Introducción al patrimonio cultural. Gijón: Trea. 
Úriz Bidegáin, N. (1999). Unidad Técnica de Diseño y Desarrollo Curricular. Recuperado de: http:// dpto.educacion.navarra.es/publicaciones/pdf/apr_coop.pdf 



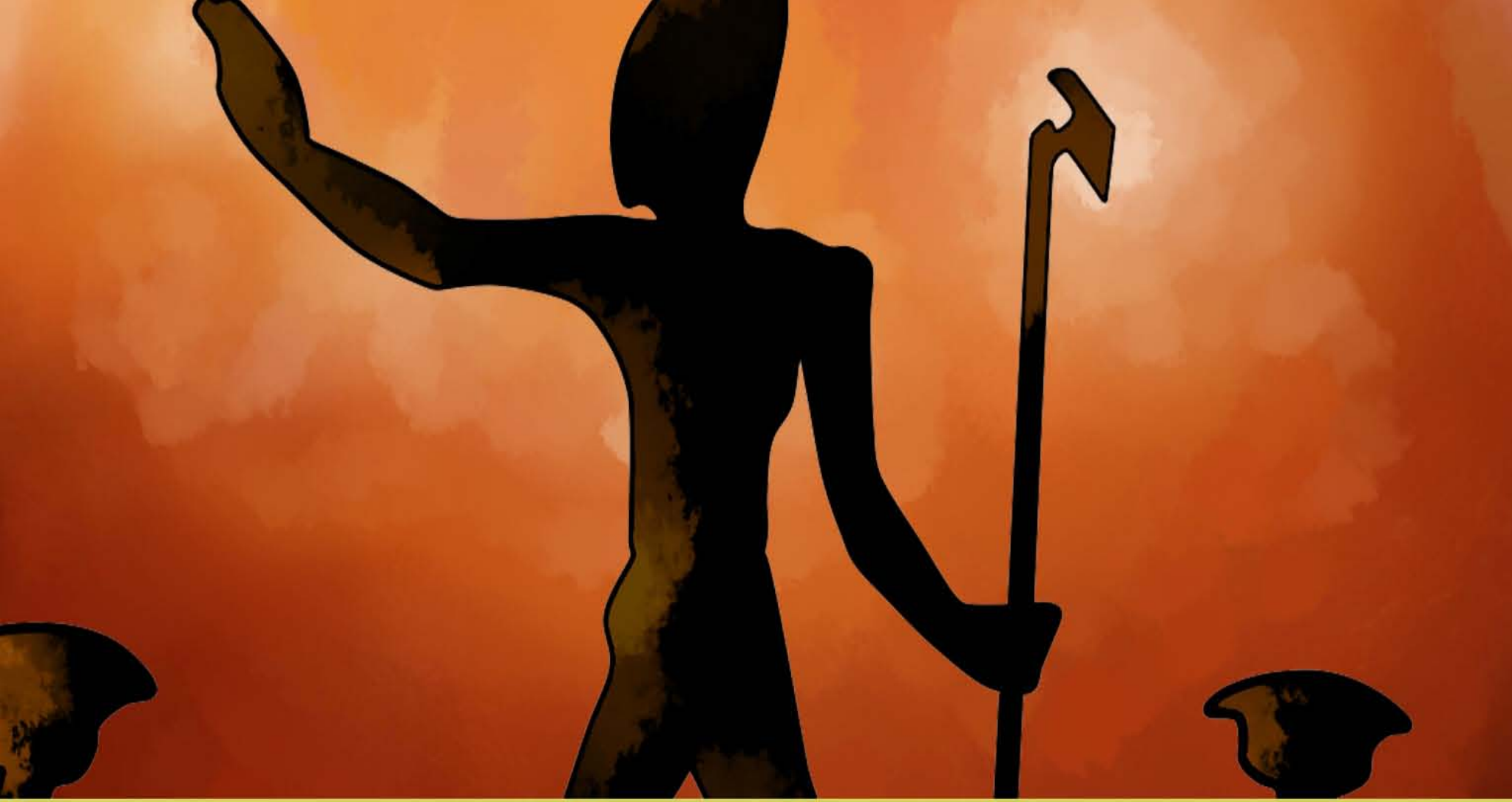

